\title{
From discovering to delivering: A critical reflection on eco-feedback, application design, and participatory research in the United Kingdom
}

\begin{abstract}
The area of Eco-Feedback has received significant attention in recent years. Whilst there have been increasing calls to move 'beyond feedback' and consider the wider social, organisational and cultural context that feedback sits within, the involvement of community members in the design process of eco-feedback applications, known as co-design, has been limited. This study addresses that research gap through working collaboratively with community members to develop an accessible eco-feedback interface. First, we conducted an online survey questionnaire with 151 respondents with distinct socio-economic characteristics and environmental knowledge to get insights into their preferences about different aspects of the eco-feedback interface. Secondly, based on the survey findings, 20 community members living in Nottingham, UK, worked collaboratively to develop interface design proposals. Finally, the design of the eco-feedback interface was finalised based on the community interface prototypes and suggestions. The developed interface contains multiple information panels with options for expanding to gain deeper levels of information and a community space allowing for community interactions and sharing of information and actions. This research sheds new light on the challenges of utilising co-design principles to build eco-feedback interfaces. Specifically, we highlight the potential for interactions between community members during the design stages to allow for the generation of innovative ideas (e.g. Integration of third-party applications) moving the interface beyond feedback leading to greater adoption and energy savings.
\end{abstract}

Keywords: Eco-feedback, energy sustainability, co-design, green ICT.

\section{Introduction}

The UK residential sector consumes approximately $27 \%$ of the country's total energy and emits around $20 \%$ of its $\mathrm{CO}_{2}$ [1]. For this reason, the UK government has implemented a wide range of measures in this sector towards meeting its $\mathrm{CO}_{2}$ emission targets. Whilst the majority of interventions have revolved around improving the thermal quality of the building envelope (e.g. retrofit), promoting proenvironmental behaviours has received increasing attention in recent years [2]. Indeed, research has found that changes in household behaviour can lead to 5-15\% savings in energy use [3].

Energy behavioural change interventions can be broadly classified into two categories; informational and structural [4]. Informational interventions, which are the most commonly discussed in the 
literature, concentrate on tackling the motivational determinants of behavioural change. In particular, they are designed to alter people's knowledge, perceptions, and norms while raising their awareness [5]. Informational strategies can be further categorised into feedback, prompting, commitment, and goal setting. However, often two or more sub-categories are combined to allow an effective implementation (e.g. feedback and goal setting) [6].

One of the informational feedback approaches that have proliferated in recent years, due to advancements in information communication technology (ICT), is Eco-feedback. Due to their monitoring capabilities, Eco-feedback systems provide occupants with useful information about their past and current energy usage patterns with different levels of temporal granularity (e.g. hourly consumption of lighting) [7]. These have the potential to reduce household energy consumption [811]. However, existing Eco-Feedback systems concentrate largely on individual households despite the fact that research has shown that fostering a sense of community ${ }^{1}$ is key to sustaining long-term behaviour change $[12,13]$. Of course, some studies have leveraged social techniques such as competition, comparison, collaboration, and social interactions in their Eco-feedback systems [14]. Again, this group of studies relies on the involvement of community members mainly in the implementation stages to test and improve a given Eco-feedback system but not in the actual design process. The involvement of stakeholders and end-users in the design stages of a service or product they might use in the future is referred to as co-design or participatory design [15]. While co-design principles have been widely adopted in different fields of study (e.g. urban planning) to increase public participation, they have not fully been considered in the design of eco-feedback systems. As designers and developers operate under certain assumptions, it is more often than not the perspectives of endusers are overlooked if they are not part of the design process [16]. In the context of communitybased eco-feedback, not involving community members in the design stages may lead to the development of inaccessible eco-feedback systems that do not meet their needs and expectations. Subsequently, such systems would struggle to sustain the community engagement in proenvironmental behaviours in the long-term. This explains why there have been increasing calls to move 'beyond feedback' and consider the wider social, organisational and cultural contexts that feedback sits within $[17,18]$.

Arnstein's ladder of participation [19] (see figure 1) is a helpful framework within which to understand stages of participation. At the bottom of her ladder is non-participation, then information provision and consultation which are still predominantly one-way forms of communication. Consultation, for

\footnotetext{
${ }^{1} \mathrm{~A}$ community is in the context of this study, refers to a group of people sharing a sense of place located in a given geographical area such as neighbourhood, town, village, or city. This group of people could share communalities such as culture, religion, values, identity, and interests[66].
} 
example, is still typically a relatively passive process which asks for people's opinions but does not necessarily engage them in the debate. Participation, noted Arnstein, should not be considered an 'add-on' but rather a set of steps to increased participation, partnership and ultimately, empowerment. Participation is normally used to refer to processes which allow people to participate in a decision by putting forward their views verbally whereas engagement goes further, suggesting an innovative and interactive, two-way process of discussion and dialogue (i.e. deliberation) to ensure that people's views inform a decision, alongside those of the expert and/or decision-maker. Therefore participation should be an innovative and interactive two-way dialogue that takes into account people's views in the decision-making process this emphasis on participation is echoed by [20], who notes that first, democracy is increased as all citizens have a right to participate and be represented in environmental decision making; second, non-experts are often more attuned to the ethical issues of a situation; and third, greater acceptance can often be achieved by involving all those affected by the particular situation. A fourth, and often overlooked benefit, is that processes of public engagement can create ideal conditions for social learning which can lead to varying degrees of behaviour change $[21,22]$. Thus, engaging the public may result in lowering people's resistance to engaging in proenvironmental behaviour [23].

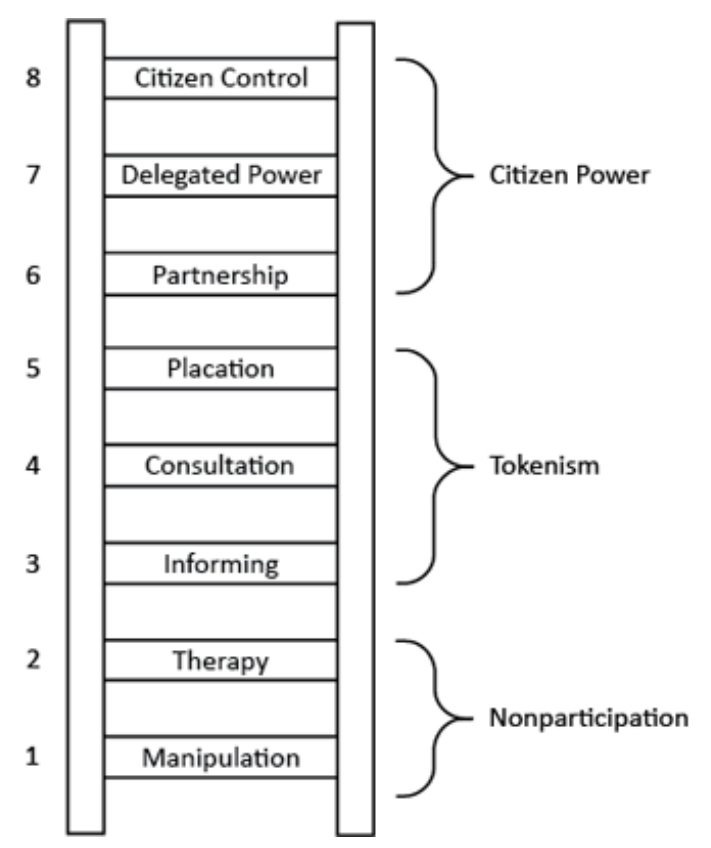

Figure 1. Arnstein's participation ladder retrieved from [19]

In response to the lack of participatory initiatives in the design process of eco-feedback applications, this research focuses on developing an accessible eco-feedback interface through a co-design 
approach involving the study researchers, Nottingham city community members, and energy experts in its design process. This work is related to the Nottingham Remourban future cities demonstrator project which is supported by Horizon 2020 [20]. Specifically, our study aligns with one of the Remourban objectives consisting of developing and restructuring technologies to promote citizen engagement. This is the rationale for selecting Nottingham as a case study. However, to frame the participatory process and ensure its effectiveness, the study used a well-established co-design framework known as the double diamond framework that originated by the UK design council [25]. This framework is discussed in more depth in the methodology section.

As noted in the double diamond framework, it is necessary to explore the wider context of a given problem before embarking on co-design activities [15]. In the context of this study, it is important to gain insight into the wider end-users' preferences about the eco-feedback interface.

The following objectives have been set to meet the study aim:

1. To gain an insight into the end-users' preferences about the design, layout, and features of the eco-feedback interface while identifying barriers to their engagement in proenvironmental behaviour.

2. To work collaboratively with the local community to develop eco-feedback interface prototypes based on the findings of objective one.

3. To finalise the design of the eco-feedback interface based on the prototypes and suggestions from the local community.

The remainder of this paper is structured into six sections. First, Section 2 reviews the literature related to eco-feedback, whereas section 3, presents the research methodology. Section 4 analyses the research findings and section 5 addresses the implication of the study findings on the design of the community-based eco-feedback interface. Finally, section 6 concludes the paper while discussing future research opportunities.

\section{Literature review}

The area of Eco-Feedback has received increasing attention in recent years. This is because several eco-feedback applications have proven to be effective for advocating behavioural change and helping occupants reduce electricity consumption (up to 20\%) [21]. Despite the lack of focus on community- 
based Eco-feedback applications [22], research in this area concentrates on the determinants of participant engagement (e.g. competitions and comparisons), data visualisation, and the level of data disaggregation [23].

First, numerous studies suggest that introducing comparisons between community members in their eco-feedback systems help promote pro-environmental behaviour [14,24]. However, others $[25,26]$ reported unsuccessful comparisons when participants have very little or no knowledge of their peers. Moreover, users often express privacy concerns about sharing their data (e.g. energy usage) with other community members [8]. Instead, they preferred self-evaluating their actual energy usage against their historical one.

Many scholars report a positive effect of social competition on occupants' engagement in energysaving activities [9,27-29]. However, the level of acceptance of such measure by certain participants and the consistency of its effect in the long-term remains open for debate in the literature [30]. For example, [9] and [29] reported $32 \%$ and up to $55 \%$ of reduction in energy consumption, respectively, when they ranked the residents of student accommodations based on their energy usage. Other studies such as [31]; however, advised that participants who disliked competition believe that introducing competition hindered their collaboration with other community members to save energy. Despite these controversies, there is a consensus in the literature that coupling competition with reward leads to positive changes in the environmental attitude of community members but only in the short-term [4]. For instance, in a study conducted by [32], the authors achieved a $20 \%$ energy reduction in student accommodation when including a competition mechanism such as ranking. However, there was a sharp decline in the engagement of residents in energy-saving activities after the scheme was over.

Due to their data sharing, geolocation and social interaction capabilities, the majority of communitybased Eco-feedback systems tend to exist in the form of a smartphone app [33], website [34], and/or integrated into a social platform [35]. While these technologies helped in promoting and triggering pro-environmental behaviour, research has shown that they can pose an obstacle especially to those with low ICT skills and/or who are privacy-conscious [36]. For example, [37] achieved a 26\% reduction in energy consumption when linking their Eco-feedback system to Twitter to send users suggestions about their energy usage. Conversely, in the GoodDeeds project [38], participants who were new to social media and/ or had a bad experience with it refused to share their energy-related data/ saving activities on it. Instead, they preferred to know about the energy usage and saving actions of others through a newsfeed widget. Similar findings were reported by [14] who encountered community distrust concerns with regards their community message board. In particular, participants with high- 
energy consumption were upset and felt that their privacy was violated when their data was shared. Part of the problem is a "one size fits all" approach of existing studies that tend to provide the same feedback and utilise the same technology to different segments who have distinct motivations and energy saving experiences [39]. This is also evident in the paucity of studies that compare the impact of different technologies (e.g. mobile app and social media) on the engagement levels of different community members.

In their research, [40] analysed 14 studies and concluded that there was no robust evidence to suggest that disaggregated energy feedback is more effective than the aggregated one. However, disaggregated energy feedback can be more impactful when participants are already motivated ("energy enthusiastic"). The findings of other scholars [41]; on the other hand, were in disagreement as they advised that energy savings made with disaggregated Eco-feedback systems were superior to when utilising the aggregated ones.

In light of the above, it is evident that the effect of different aspects of Eco-feedback on the end-users' participation in pro-environmental activities is reported inconsistently in the literature. This represents another motivation behind exploring the views and preferences of the wider audience about the features of the envisaged Eco-feedback interface and without making assumptions. This is while identifying any obstacles that prevent them from engaging in pro-environmental behaviour. In this regard, the nature of preferences and obstacles to explore has been informed by key themes identified from the analysis of the literature of eco-feedback. These themes are as follows: familiarity with ICT, Eco-feedback technology preferences, privacy, social interaction, and type of feedback.

\section{Methodology}

Owing to the participatory nature of this research, it is vital to engage different community members and project stakeholders in the collaborative knowledge building process alongside considering their views and preferences. Thus, our research design draws on the double diamond framework (figure 2), a well-established model for delivering participatory research [43]. The backbone of the double diamond framework lies in its emphasis on "divergent" and "convergent" thinking. Divergent thinking consists of gaining insights into the problem or subject matter from the wider audience, whereas convergent thinking consists of refining and narrowing down the generated insights and perspectives to produce an optimal solution [42]. As shown in figure 2 (above), this thinking process occurs twice in the double diamond framework resulting in four stages namely: discover, define, develop, and deliver. A combination of qualitative and quantitative research methods, including survey 
questionnaire and participatory focus groups (workshops), were utilised. More details about each phase in relation to the undertaken study are discussed the below sub-sections.

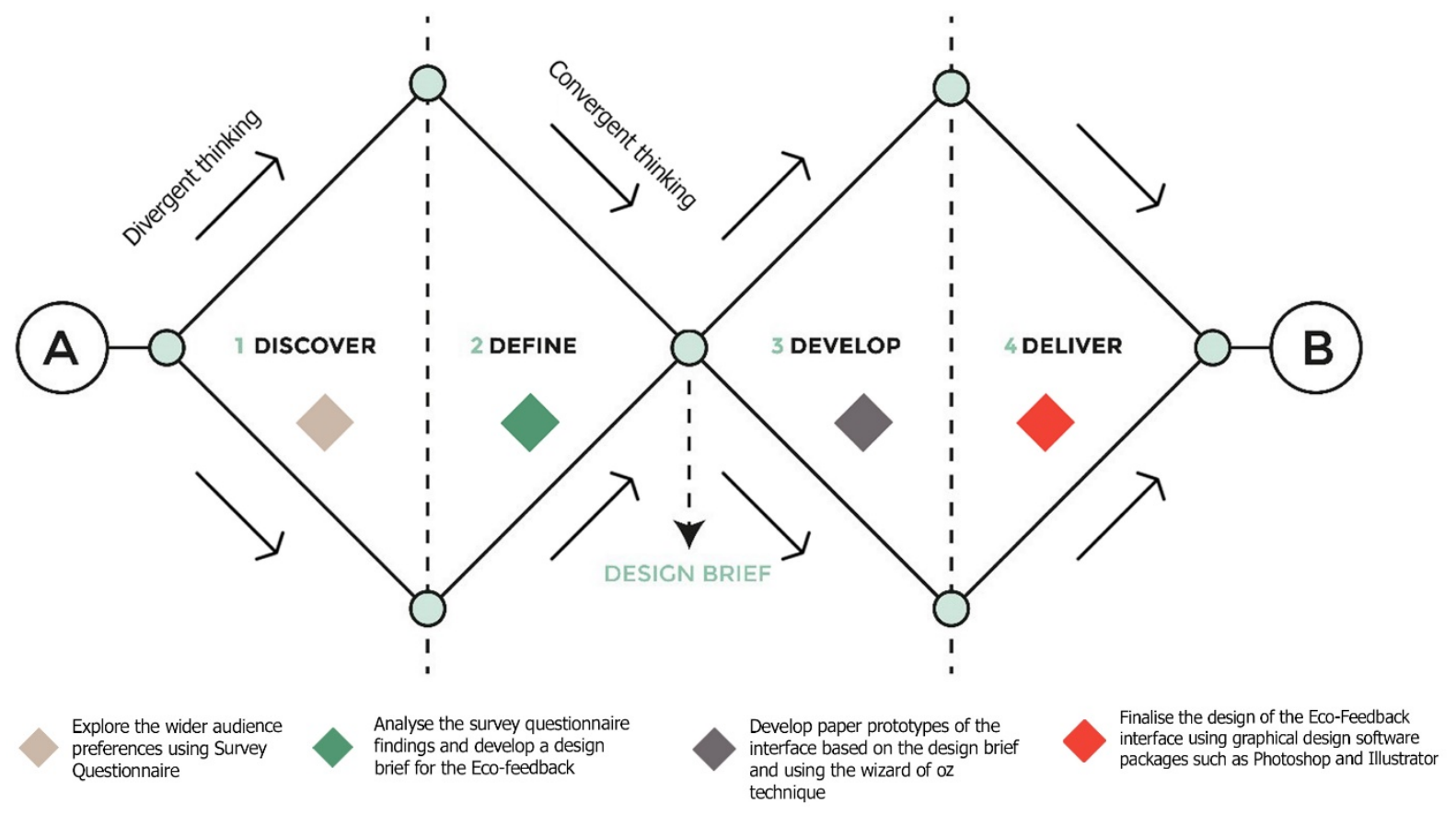

Figure 2. The Double Diamond framework, adapted from [42]

\subsection{Phase 1: "Discover" the wider audience preferences and perceptions}

In line with the double diamond framework, the "discover" stage comprised building insights into the preferences of the wider end users in the UK about the features of the potential eco-feedback interface. However, identifying any obstacles to their engagement in pro-environmental behaviour is also deemed necessary to reflect on and address in the design of the eco-feedback interface. There is a wide range of research methods that can be utilised in the "discover" stage such as interviews, focus groups, and survey questionnaires [42]. However, in this study, a survey questionnaire was adopted to enable reaching a wider audience within a short period and in an efficient manner. To help quantify the responses, the study's online survey questionnaire comprised mostly close-ended questions except for one open-ended question (see appendix A). The main questions in the survey revolved around the key themes identified in the literature. These are as follows: familiarity with ICT, Ecofeedback technology preferences, privacy, social interaction, and type of feedback. As there are disagreements in the eco-feedback literature about the relationship between these themes and the end-users' engagement in pro-environmental behaviour (section 3), getting an insight to the wider audience perspectives helped clarify the inconsistencies. In addition to the main questions, questions 
related to the participants' general knowledge about environmental issues were added to the survey. According to [44], these type of questions acquaint participants with surveys covering energy sustainability and innovative technologies. Demographic questions were included in the survey to understand the characteristics of the sample and determine how responses may vary between different sub-groups (e.g. male and female). For more information on the survey questions, please refer to Appendix A.

Although the focus of this stage was to gain insights into the wider audience perceptions and preferences, the generalisability of findings has limitations [45]. It was challenging to ensure that every member of the population was given an equal chance to participate in the survey under the limited time and resources present in our study. For those reasons, we utilised a heterogeneity sampling, which is a non-probabilistic sampling technique. The heterogeneity sampling allows for multiple perspectives of participants to be presented. Furthermore, it is adequate when it is not possible to draw a random sample [46].

The survey was distributed to the public using the $\mathrm{Jisc}^{2}$ service, which is a platform to promote participation in academic research studies [47]. Jisc sent the survey to different participants living in the UK using their existing databases and social media platforms [47]. To increase participation, the researchers introduced incentives in the form of Amazon vouchers. The survey responses have been analysed using descriptive and inferential statistical techniques such as Chi-square.

\subsection{Phase 2: "Define" the design brief of the Eco-feedback user-interface}

This phase entailed translating the wider audience preferences about the developed eco-feedback interface and obstacles facing their engagement in pro-environmental behaviour into a design brief. This helped the project stakeholders, including Nottingham city community members, develop interface prototypes in the subsequent phase. The brief should be clear and concise containing information about the aim/objective(s) of the eco-feedback interface, necessary contextual information about the project, target audience, and interface specifications. Whenever possible, the development of design specifications was based on different participants' suggestions to ensure a democratic participation process.

\subsection{Phase 3: "Develop" Eco-feedback user-interface prototypes}

\footnotetext{
2 Jisc is not-for-profit organisation that delivers digital solutions for UK higher education and research [47].
} 
This stage consisted of collaboratively working with Nottingham city community members, energy experts, and the researchers to develop design prototypes of the eco-feedback interface based on the design brief created in phase 2. To attain this objective, two participatory workshops were held at Nottingham Trent University in May 2019 and were audio-recorded and transcribed. Twenty participants have taken part over both workshops (10 in each workshop), 14 of which were randomly recruited via the Jisc participation call portal under the condition they live in Nottingham. The remaining participants included the project researchers and three energy experts from Nottingham Energy Partnership (NEP) ${ }^{3}$. It is worth noting that the attendees had distinct demographic profiles and backgrounds. Furthermore, they self-reported different levels of knowledge of energy sustainabilityrelated topic (see table 1 below).

Table 1. Profile of the focus groups' participants

\begin{tabular}{|c|c|c|c|c|c|c|c|c|c|}
\hline \multirow[t]{3}{*}{ 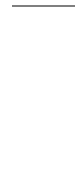 } & \multirow[t]{3}{*}{ ID } & \multirow[t]{3}{*}{ Age } & \multirow[t]{3}{*}{ Education } & \multicolumn{2}{|l|}{ Self-reported } & \multirow[t]{3}{*}{ ID } & \multirow[t]{3}{*}{ Age } & \multirow[t]{3}{*}{ Education } & Self-reported \\
\hline & & & & Knowledge of & & & & & Knowledge of \\
\hline & & & & Similar topics & & & & & Similar topics \\
\hline \multirow{10}{*}{ 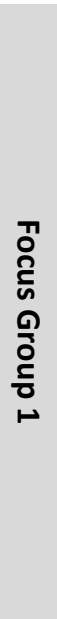 } & P1 & $35-44$ & Bachelor & Moderate & \multirow{10}{*}{ 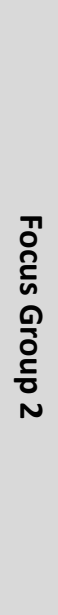 } & P11 & $45-54$ & Bachelor & Expert \\
\hline & $\mathrm{P} 2$ & $25-34$ & $\mathrm{MSc} / \mathrm{PhD}$ & Good & & P12 & $25-34$ & $\mathrm{MSc} / \mathrm{PhD}$ & Moderate \\
\hline & P3 & $21-24$ & College & Moderate & & P13 & $21-24$ & Bachelor & Little \\
\hline & P4 & $35-44$ & Bachelor & Little & & P14 & $35-44$ & $\mathrm{MSc} / \mathrm{PhD}$ & Expert \\
\hline & P5 & $<21$ & College & Moderate & & P15 & $<21$ & College & Good \\
\hline & P6 & $45-54$ & College & Little & & P16 & $21-24$ & Bachelor & Good \\
\hline & P7 & $55-64$ & Bachelor & Expert & & P17 & $24-34$ & College & Little \\
\hline & P8 & $25-34$ & $\mathrm{MSc} / \mathrm{PhD}$ & Very Good & & P18 & $35-44$ & Bachelor & Very Good \\
\hline & P9 (PI) & $25-34$ & $\mathrm{MSc} / \mathrm{PhD}$ & Very Good & & P9 (PI) & $25-34$ & $\mathrm{MSc} / \mathrm{PhD}$ & Very Good \\
\hline & P10 (RA) & $25-34$ & Bachelor & Good & & P10 (RA) & $25-34$ & Bachelor & Good \\
\hline
\end{tabular}

Note: PI (Principle investigator)/ Ra (Research assistant)

To maximise the number of generated interface prototypes within the study limited time, the two participatory focus groups were purposefully designed to be independent of each other. More precisely, the participants of each workshop have undertaken similar tasks with the same design brief. Following the double diamond framework, the first task consisted of delivering a presentation by the

\footnotetext{
${ }^{3}$ Nottingham Energy partnership is an independent fuel poverty charity and home improvement agency established in 1998. In 2014, they have received the Queen's Award for climate change for successfully delivering key projects around tackling fuel poverty and reducing $\mathrm{CO} 2$ emission such as REMOURBAN [67].
} 
principal investigator covering the elements in the design brief (see phase 2 ) in more depth. Following that, participants performed the below actions iteratively:

(1) Developed paper prototypes of the user-interface using different stationery items such as sticky notes. To allow an iterative design process with short releases, common community-based Ecofeedback interface elements such as energy consumption graphs, 2D/3D maps, weather widget, and buttons, were provided for the participants.

(2) Evaluated the paper prototypes using peer-discussions coupled with the wizard of Oz prototyping technique [48]. This technique permits users to explore the design and test the usability of the ecofeedback interface prototypes without the need for any computer programming to be conducted. For example, if users are testing the usability of the application menu, they can 'pretend click' on the application menu icon and mimic the reaction of the application by showing another paper panel that contains elements such as user profile, settings, logout, etc.

(3) After the focus groups' participants evaluated the produced prototypes, they were required to improve them while considering any ideas/suggestions from the peer-discussions.

\subsection{Phase 4: "Deliver": Finalising the design of the community-based eco-feedback user-interface}

Following the development of several interface prototypes and the generation of new ideas/ suggestions in the participatory workshops, this phase involved the development of a consensual community-based eco-feedback interface. To attain this objective, the researchers carefully examined the generated interface prototypes and the focus groups' transcripts. In this respect, similarities and difference between the prototypes were identified. After that, suggestions/ideas that were discussed in the focus groups but do not exist in the interface prototypes were considered. Based on that, a combination of well-known graphics computer applications such as Photoshop, InDesign, and illustrator was utilised to develop the final community based eco-feedback interface design.

\section{Findings and discussion}

\subsection{Findings of phase 1}

This sub-section discusses in detail the preferences of the wider audience regarding the developed eco-feedback interface through the analysis of the survey questionnaire findings. However, this is preceded by an analysis of the socio-economic characteristics of the participants and their degree of environmental knowledge. 


\subsubsection{Sample characteristics}

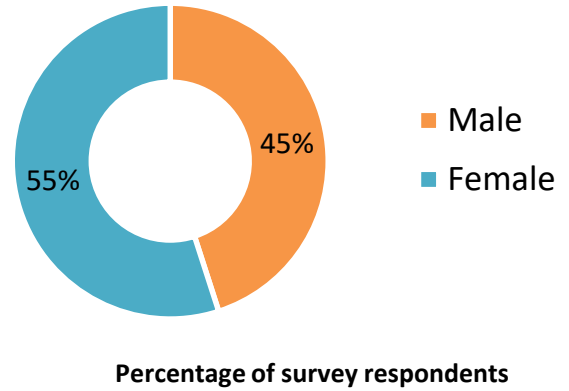

Figure 3. Gender distribution of the survey respondents

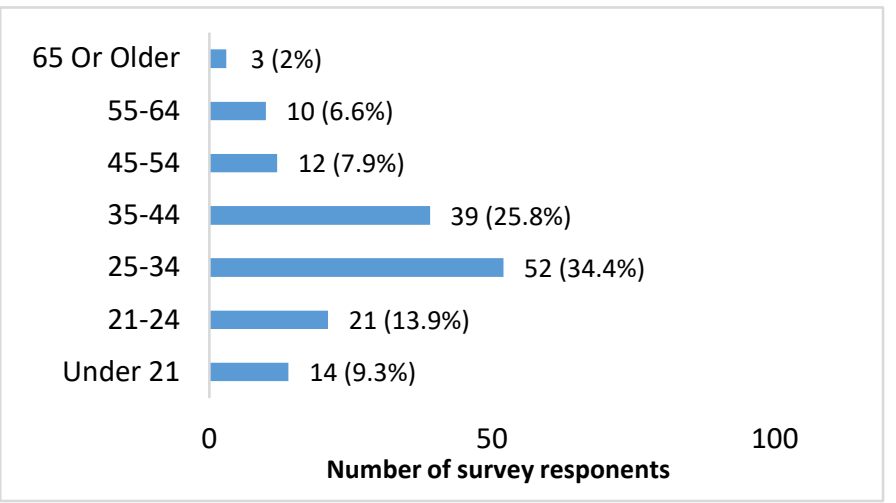

Figure 4. Age distribution of the survey respondents

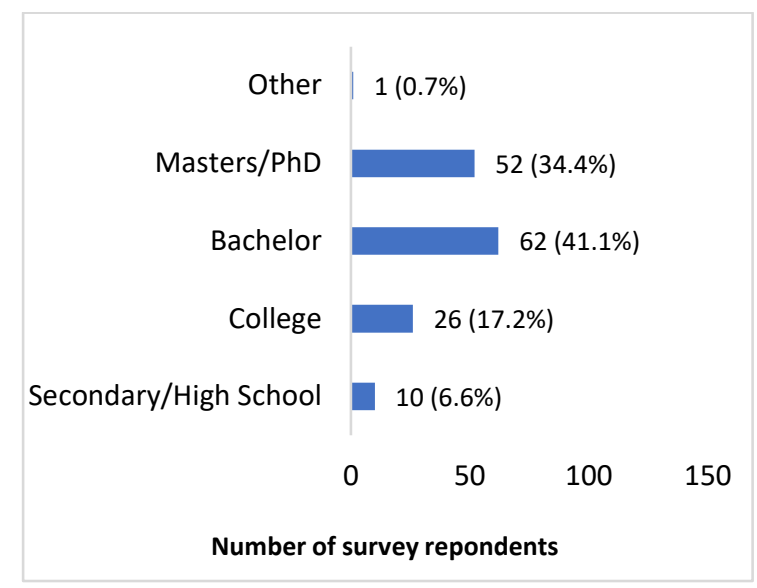

Figure 5. Educational profile of the survey participants

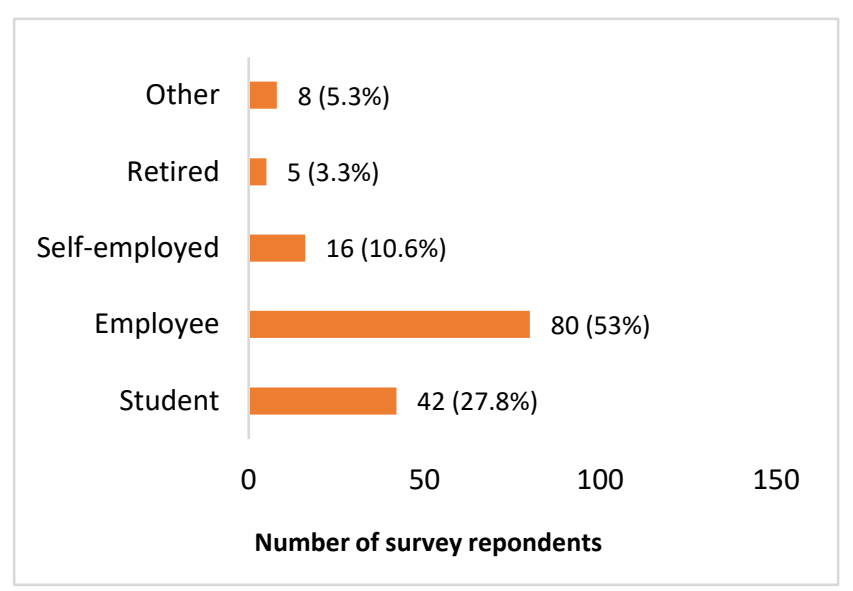

Figure 6. Employment status of the survey respondents

Although the ideal of sample representativeness is an important aspect of a rigorous survey design as noted by [49], it was difficult to obtain a fully representative sample of the whole UK population). Therefore, the survey sample is unlikely to be fully representative of the wider population on important socio-demographic characteristics such as age, gender, and educational attainment profile. However, as indicated in section 3.1, the main objective of conducting this survey questionnaire was to obtain a broad spectrum of ideas and opinions rather than directly representing people's views to make generalisations.

151 participants with various socio-economic characteristics, as shown in the figures 3-6, filled the survey questionnaire. Overall, there was a good distribution between the proportion of male (45\%) and female respondents (55\%) as shown in figure 3 . However, $60.2 \%$ of the surveyees were aged 
between 25 and 44 , whereas $14.2 \%$ had $45-64$ years (figure 4 ). This could be attributed to the fact that the survey was mainly diffused through social media and networks, which are often used by younger groups. Regarding their level of education, the majority of participants possess at least a University degree. In particular, $41.1 \%$ of them had a bachelor degree, $34.4 \%$ achieved an MSc or PhD, $17.2 \%$ have a college qualification, and $6.6 \%$ obtained a secondary/high school-related qualification (figure 5). Finally, (53\%) were employed, whereas $27.8 \%$ were students and $3.3 \%$ were retired (figure 6 ).

\subsubsection{Environmental Knowledge and awareness of the participants and their familiarity with ICT}

As discussed previously, the survey questionnaire included questions that helped identify the environmental knowledge and awareness of the respondents and which covered the following areas:

- General knowledge about residential energy saving

- Responsibility for energy saving

- Reasons for the lack of engagement in pro-environmental behaviour

- Recent actions made to improve energy efficiency

Overall, as shown in figure $7,51 \%$ of the respondents claimed to have moderate knowledge about home energy saving and $33.8 \%$ said to have a good to very good knowledge on the topic. Further investigation using a Chi-square test confirmed that people with $\mathrm{MSc} / \mathrm{PhD}$ education are more likely to be very knowledgeable about domestic energy-saving $X^{2}(11.089, \mathrm{p}<.01)$. As expected and in line with the findings of [50], the vast majority of respondents (83\%) felt responsible for saving energy (figure 8). After conducting a Chis-square test, it was found that people claiming to have a good/ very good knowledge are more likely to feel responsible about reducing their energy usage $x^{2}(6.275, \mathrm{p}<$ .012) which was in agreement with the findings of [51].

Interestingly, as illustrated in figure 9, respondents attributed the low engagement of households in pro-environmental behaviour primarily to the lack of information on energy savings $133.4 \%$ of responses) and to time and availability to a lesser degree (25.1\% of responses). Based on that, the developed eco-feedback system should focus on providing useful information and suggestions on domestic energy saving. This is while opting for a simple, clear, and straightforward user-interface as advised by a recent study, which found a significant negative correlation between the energy-saving levels of busy households and the complexity of eco-feedback systems' user-interface [52].

Regarding actions taken recently to improve energy efficiency, the majority of the respondents reported actions revolved around switching to energy-efficient LED lighting and improving heating 
controls (e.g. heating only occupied rooms) as depicted in figure 10. On the other hand, few respondents reported actions such as upgrading to efficient appliances and boiler. However, none of the revealed actions covered initiatives at the community level such as neighbourhood renewable energy networks. According to [53], this could be attributed to the fact that a large number of environmental campaigns advocate individual instead of collective environmental change which supports the development of our community-based eco-feedback application.

As expected from analysing the age profile of the surveyees, $74.8 \%$ of them were very comfortable with ICT technology, whereas only $2.6 \%$ were not comfortable (figure 11). However, a Chi-square test advised no significant relationship between age and familiarity with ICT.

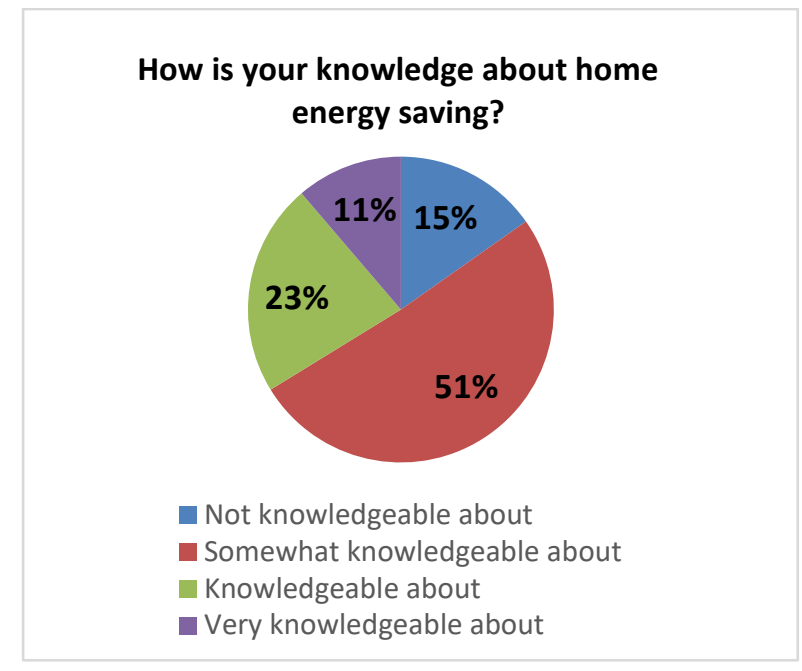

Figure 7. The respondents' Self-reported knowledge about energy saving

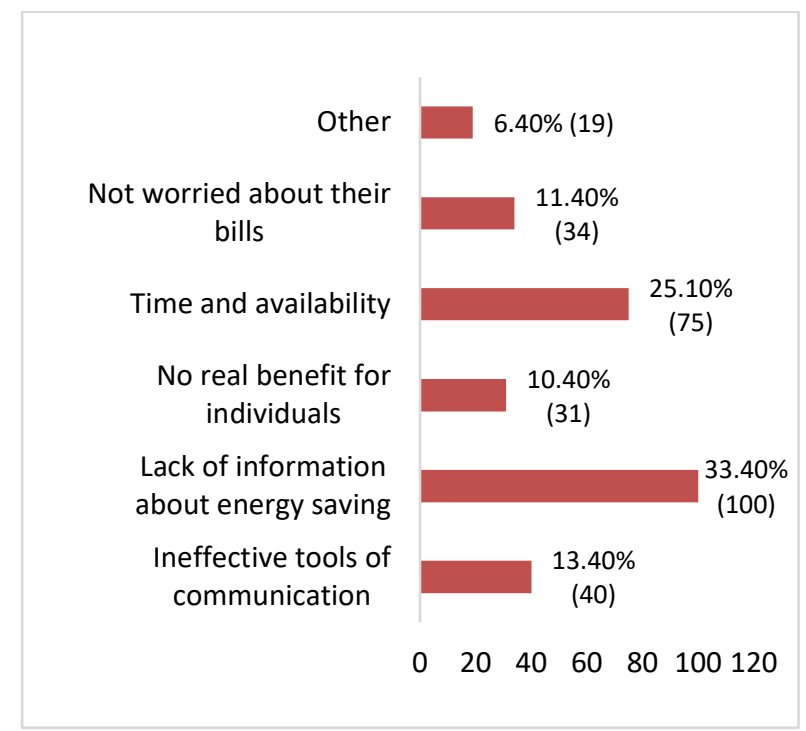

Figure 9. Surveyees' opinions about the lack of engagement in pro-environmental behaviour

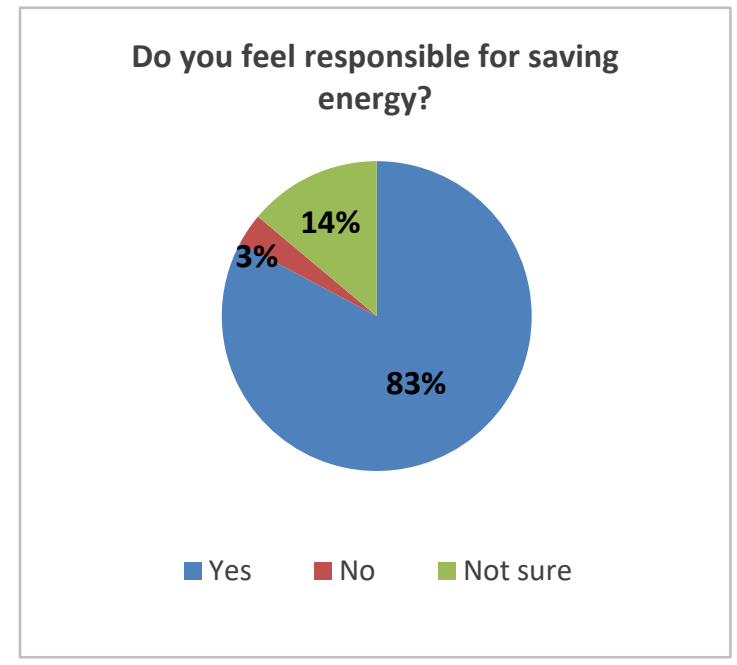

Figure 8. The participants' degree of responsibility for saving energy

\section{What actions have you made recently to save energy?}

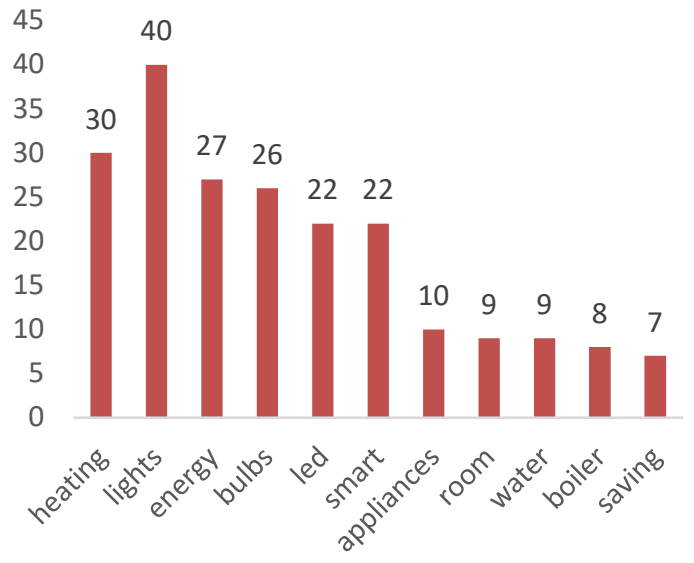

Figure 10. The word frequency in the household answers about their recent actions to save energy. 
How comfortable are you with technology such as computers and smartphones?

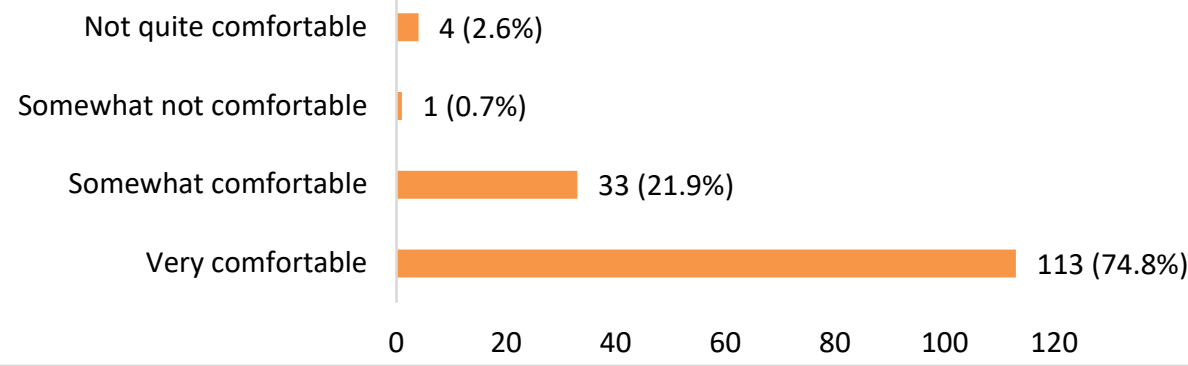

Figure 11. The level of familiarity of participants with Information technology.

\subsubsection{Participants eco-feedback preferences and perception}

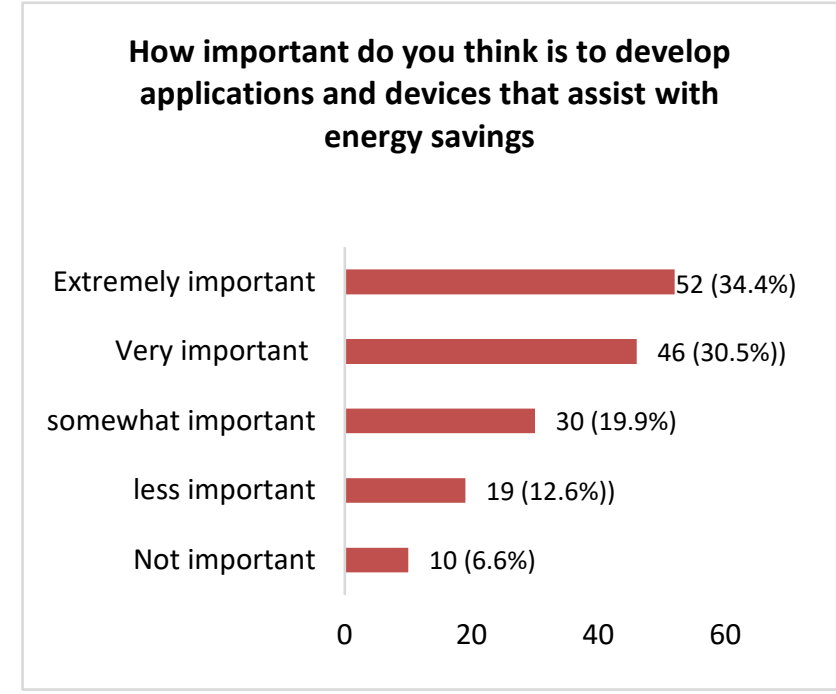

Figure 12. Participants' opinions about developing applications to assist domestic energy saving

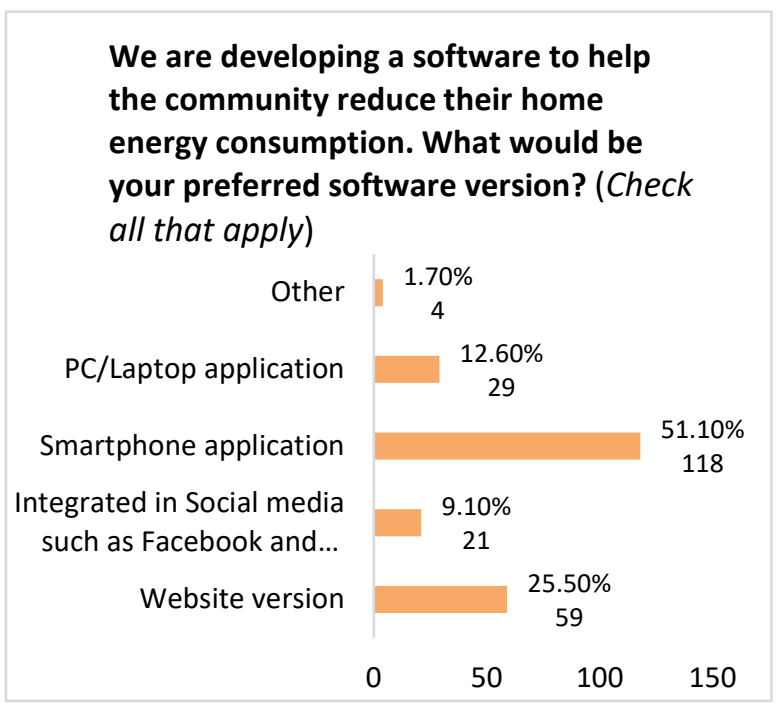

Figure 13. The preferred eco-feedback application by the survey respondents

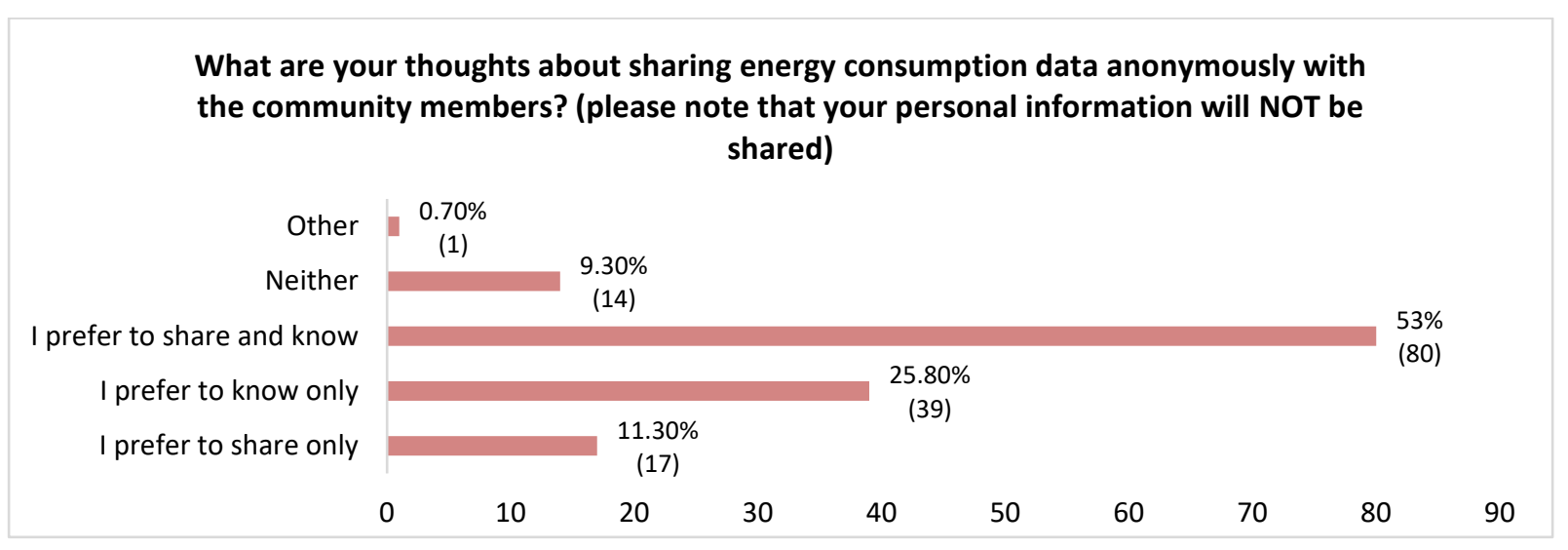

Figure 14. The respondents' opinions about the sharing of data with other community members 
The analysis of the previous sub-section has shown that the survey respondents, in general, had a moderate to a very good environmental awareness, although there was a clear lack of community sense in their reported actions. This was also reflected in their belief in the importance of developing software and hardware to promote pro-environmental behaviour. In this respect, $65 \%$ believed that it is extremely important to develop applications and devices to help them save energy (figure 12). After expressing our intention to develop a community based eco-feedback system, approximately $51 \%$ gravitated towards a smartphone version, whereas only $9.1 \%$ of them preferred a social media plugin (see figure 13). This could be an indication of privacy concerns amongst respondents, even though $74.8 \%$ of the respondents were very comfortable with ICT and familiar with social media platforms given their age profile. As noted by $[14,38,54]$, being familiar with social media does not necessarily lead to acceptance of sharing information about energy consumption with others.

Since privacy and data sharing are key aspects to consider when designing a community-based ecofeedback system, respondents were asked whether they preferred to share data anonymously with other community members. As depicted in figure 14 (above), More than half (53\%) of the respondents did not mind sharing and knowing about others, whereas 9.3\% preferred neither options. Following a Chi-Square test, it was found that people with a Bachelor degree or lower are more likely to resist sharing data $X^{2}(6.370, \mathrm{p}<.05)$. Considering that low educational attainment proved to be correlated with low energy saving levels in many studies [55], it is important to incorporate features that help this group engage in energy-saving activities. This may include comparisons with the average energy usage of similar households (e.g. $+30 \%$ above average).

Although there have been increasing calls to move beyond providing feedback, a large number of existing eco-feedback systems are confined to visualising the present and current usage of households without necessarily proving suggestions/tips to help them become more efficient users [56]. For this reason, our survey questionnaire measured the wider end-users' acceptance to receiving Ecosuggestions/tips including the ones from external sources such as videos and blogs. Overall, roughly $65 \%$ of the respondents preferred to receive Eco-suggestions, whereas $0.66 \%$ refused (figure 15 below). However, approximately $30 \%$ were open to suggestions but as long as they do not affect their comfort. This advises that the envisaged Eco-feedback system should be equipped with a multi-criteria optimisation model to allow the generation of eco-suggestions/tips without sacrificing users' comfort. In addition to the suggestions provided by our eco-feedback interface, $49 \%$ of the respondents believed that obtaining suggestions from external sources is extremely/ very important, whereas $26.5 \%$ thought it was somewhat important (figure 16). $24.5 \%$ of the participants; however, advised that this measure was not important/ not important at all. Following a cross-tabulation analysis, it was 
found that $90 \%$ of this group were those who did not feel responsible/ not sure about saving energy. This could be an indication of their lack of awareness about pro-environmental behaviour. However, since the outcome of the Chi-Square test indicated that this association was not significant, more research is needed in that respect.

Apart from their acceptance of eco-suggestions, respondents did not have any particular preferences with regards the type of information that should be known and/or shared. First, the respondents preferred to know/share information about their electricity ( $42 \%$ of answers) and gas (36\% of answers) as depicted in figure 17. The lower percentage of those who chosen to know/share information about their gas usage could be related to the non-presence of gas in their dwellings. Interestingly, 22\% of the participants' answers revolved around knowing/sharing information about hot water consumption. Secondly, the respondents found both aggregate and disaggregate information equally important (figure 18). More precisely, $63.6 \%$ of respondents preferred to receive/share information about their aggregate energy usage, whereas roughly $58 \%$ on average were keen on knowing and sharing disaggregate information. This includes information about their heating system, home appliances, and home energy rating. This suggests that the Eco-feedback interface should offer end-users both aggregate and disaggregate information while providing a certain degree of flexibility to allow them to be in control of the desired level of detail to be known or shared with others in their community. Apart from that, $60.3 \%$ of the surveyees expressed an interest in sharing/knowing green actions. Interestingly, 5.3\% of the participants requested other types of information. In this regard, $25.7 \%$ of this additional information included suggestions on real-time energy usage, whereas $74.3 \%$ of this additional information revolved around time-of-use tariffs such as when is cheaper to use electricity. Similar findings were reported by the UK citizens advice bureau [57] who surveyed 502 participants and found that poor information about time-of-use tariffs is one of the reasons behind $51 \%$ of the participants refusing/failing to successfully shift their demand. This indicates the importance of time-of-use tariffs related information in our Eco-feedback interface, although only $3.94 \%$ of the participants suggested it. Nevertheless, future users of the developed should be given the option to enable/disable information about time-of-use tariffs to ensure the preferences of certain groups are considered.

Finally, $45 \%$ of the respondents believe that ranking households based on their energy consumption would help them engage in energy-saving activities (see figure 19). On the other hand, 35.8\% suggested that ranking should be coupled with a reward mechanism to be effective. Conversely, $20 \%$ perceived ranking as non-effective for promoting pro-environmental behaviour. After further investigation, it was found that people aged 25-34 are more likely to gravitate towards rewards $X^{2}$ 
(39.642, $\mathrm{p}<.01)$. These findings align with several studies in the literature suggesting that reward schemes can be effective when addressing the lack of engagement of the youth population in community and environmental activities [58]. In contrast to that, no significant associations have been found between the group that answered no to ranking and their socio-economic factors. Thus, more research is needed in that respect.

The software that we are developing can give you suggestions on home energy saving. Would you consider those suggestions in order to save your home energy consumption?

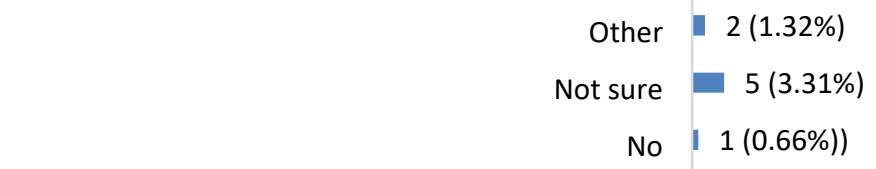

Yes, but as long as the suggestions do not affect my $45(29.8 \%)$

Yes, I would

$$
\text { (a) }
$$$$
0
$$$$
20
$$$$
40
$$

60

80

$98(64.9 \%)$

Figure 15. The survey participants' view on receiving suggestions on home energy saving

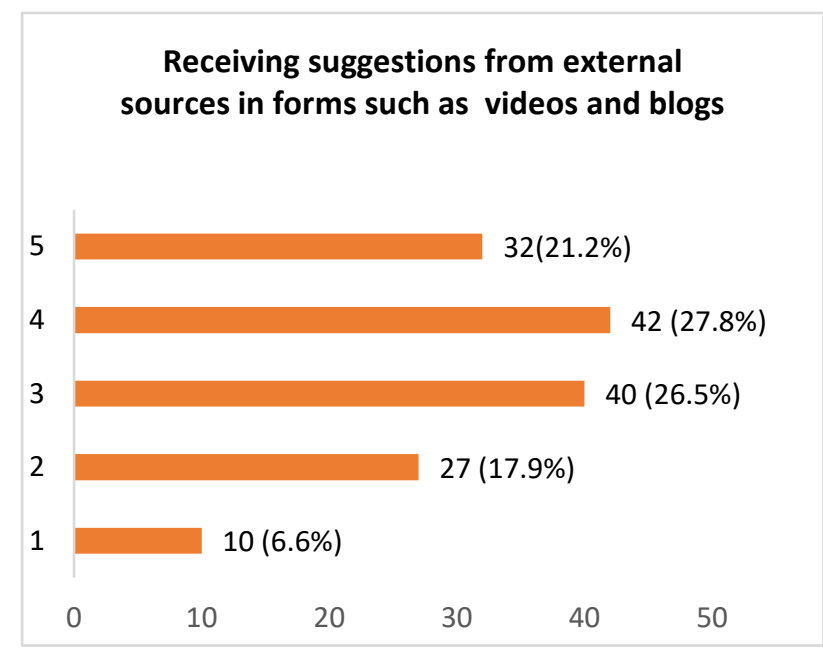

Figure 16. The surveyees views on the importance of including suggestions from external sources in forms such as videos and blogs (where 1 is the least important and 5 is the most important).

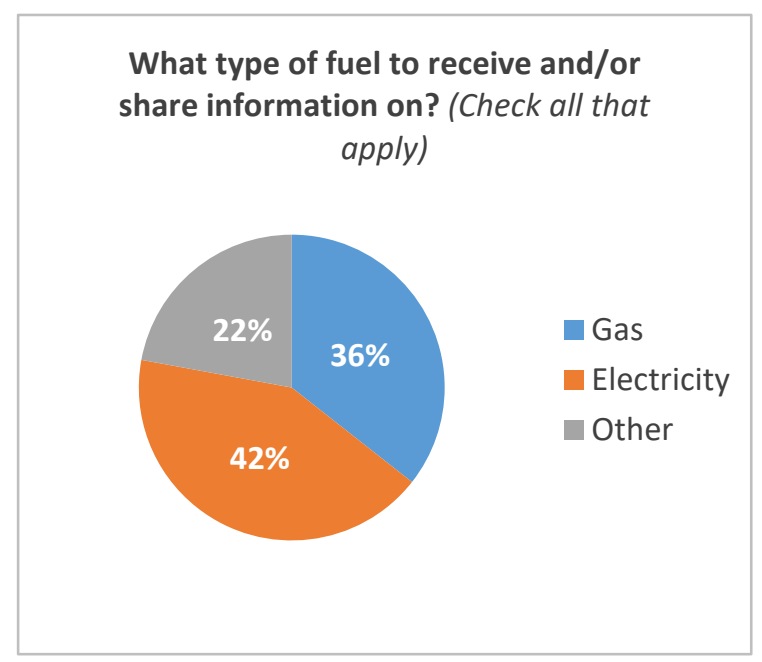

Figure 17. The surveyees' preferences about the type of fuel to receive/share information on 
What types of information that you are willing to share/know? (Check all that apply)

Other

Actions made to save energy consumption (e.g. changing old light bulbs to LED)

Your home energy rating (e.g. A+, C, D, etc...) Information about your main home appliances (e.g. Fridge and Cooker)

Information about your heating system (e.g. Type of boiler)

Quantity of your energy usage in KWh (meter readings)

Cost of your energy usage
(8)

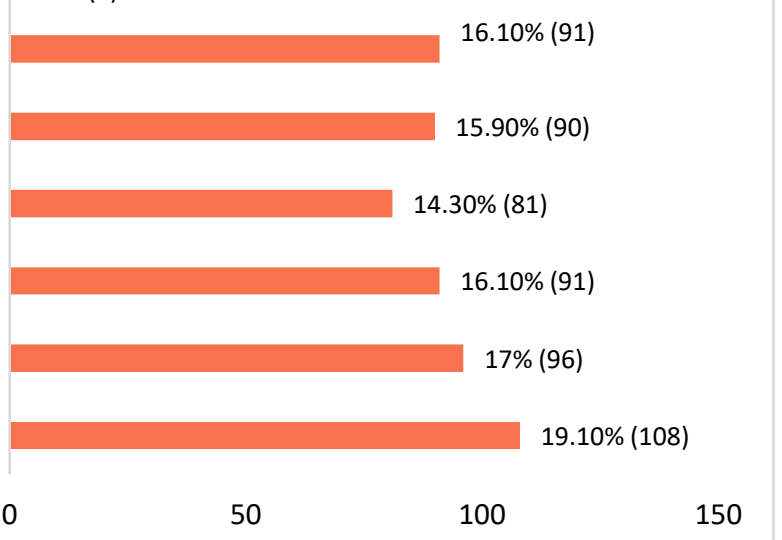

Figure 18. Surveyees' preferences with regards information type to share/ know (multiple answer reported)

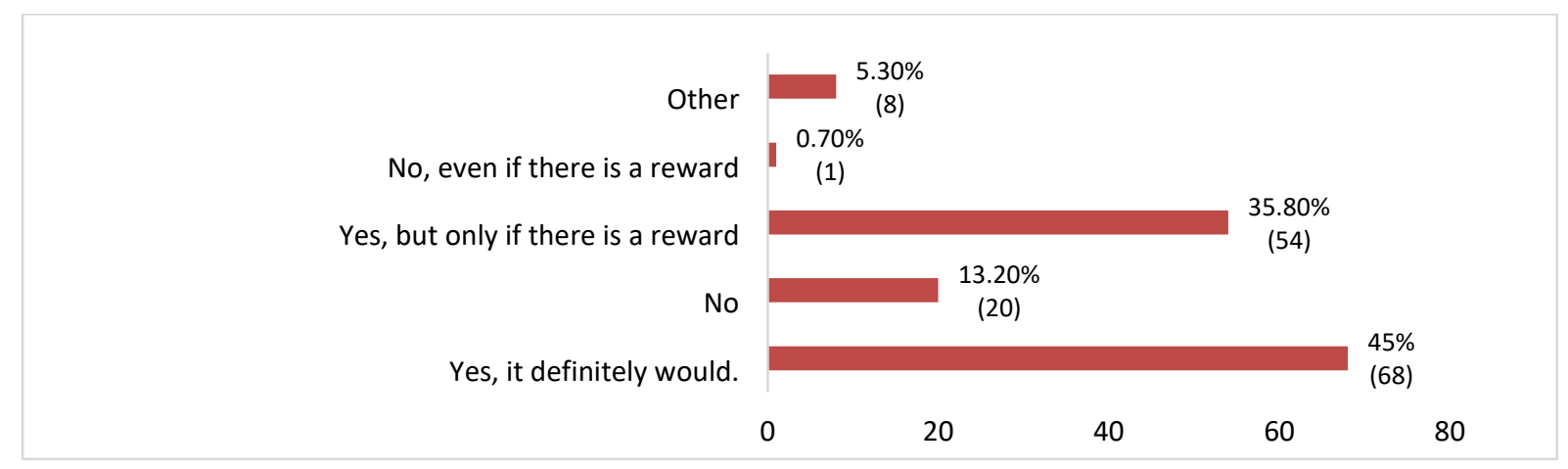

Figure 19. The survey respondents' views on the importance of ranking

\subsection{Development of the Eco-feedback interface design brief (phase 2)}

As indicated in section 3.2, a design brief was developed based on the analysis of the survey questionnaire results. This brief informed the workshops' participants in phase 3 about the aim and objectives of the project and guided them their design of the interface prototypes. Tables 2 and 3 illustrate the list of specifications issued to the workshop participants', where the second column represents the preferences of the survey respondents. Conversely, column 3 provides recommendations from the researchers based on the analysis of the survey questionnaire. 
Table 2. Eco-feedback interface design specifications (part 1)

\begin{tabular}{|c|c|c|}
\hline & Opinions of the survey respondents & $\begin{array}{l}\text { Recommendations from the researchers } \\
\text { based on the survey analysis }\end{array}$ \\
\hline $\begin{array}{l}\text { The version of the Eco-feedback } \\
\text { interface }\end{array}$ & $\begin{array}{l}\text { - } 51.10 \% \text { smartphone version } \\
\text { - } 25.5 \% \text { web version } \\
\text { - } 12.6 \% \text { pc/laptop version } \\
\text { - } 9.1 \% \text { social media plugin }\end{array}$ & $\begin{array}{l}\text { You should focus on producing a } \\
\text { Smartphone version. Other versions are } \\
\text { going to be developed in the future. }\end{array}$ \\
\hline $\begin{array}{l}\text { Data sharing with community } \\
\text { members }\end{array}$ & $\begin{array}{l}\text { - } 53 \% \text { preferred to know and share data } \\
\text { with others } \\
\text { - } 9.3 \% \text { did not want to know and share } \\
\text { data with others }\end{array}$ & $\begin{array}{l}\text { Users should be given an option to } \\
\text { specify whether they would like to know } \\
\text { and/or share data with others or not. To } \\
\text { help those who chose not to know and } \\
\text { share data engage in pro-environmental } \\
\text { behaviour, measures including } \\
\text { comparisons with the average energy } \\
\text { usage of similar households, need to be } \\
\text { developed. }\end{array}$ \\
\hline Eco-suggestions/tips & $\begin{array}{l}\text { - } 65 \% \text { wanted to receive eco } \\
\text { suggestions/tip. } \\
\text { - } 29.8 \% \text { wanted to receive eco- } \\
\text { suggestions/tip but if they do not } \\
\text { affect their comfort. }\end{array}$ & $\begin{array}{l}\text { The developed Eco-feedback interface } \\
\text { should provide users with Eco- } \\
\text { suggestions/tips. } \\
\text { As some users noted that they do not } \\
\text { want the suggestions to affect their } \\
\text { comfort, a future plan is to develop a } \\
\text { multi-criteria optimisation model inside } \\
\text { the interface. }\end{array}$ \\
\hline $\begin{array}{l}\text { Eco-suggestions/tips from } \\
\text { external sources (e.g. videos and } \\
\text { blogs) }\end{array}$ & $\begin{array}{l}\text { - } 49 \% \text { believed that it is very / } \\
\text { extremely important to receive } \\
\text { suggestions from external sources } \\
\text { - } 24.5 \% \text { believed that suggestions } \\
\text { from external sources are not } \\
\text { important. }\end{array}$ & $\begin{array}{l}\text { Suggestions from external sources should } \\
\text { be part of the developed Eco-feedback } \\
\text { interface. } \\
\text { Those who refused to receive } \\
\text { suggestions/tips from external sources } \\
\text { did not feel responsible/ were not sure } \\
\text { about saving energy. Thus, we should } \\
\text { develop features that raise their pro- } \\
\text { environmental awareness. }\end{array}$ \\
\hline $\begin{array}{l}\text { Type of fuel to share and receive } \\
\text { information about }\end{array}$ & $\begin{array}{l}\text { - know/ share information about their } \\
\text { electricity usage ( } 42 \% \text { of the answers) } \\
\text { - know/ share information about their } \\
\text { gas usage ( } 36 \% \text { of the answers) } \\
\text { Share/know information about other } \\
\text { fuel sources ( } 22 \% \text { of the answers). } \\
\text { This was mainly about hot water } \\
\text { consumption }\end{array}$ & $\begin{array}{l}\text { Users should know and share } \\
\text { information related to electricity, gas, } \\
\text { and hot water consumption. However, } \\
\text { they should have given the option to } \\
\text { customise it. }\end{array}$ \\
\hline $\begin{array}{l}\text { Type of information to be } \\
\text { known/shared }\end{array}$ & $\begin{array}{l}\text { - Quantity of energy usage ( } 17 \% \text { of the } \\
\text { responses) } \\
\text { - Cost of used energy ( } 19 \% \text { of the } \\
\text { answers) } \\
\text { - Information about home appliances } \\
\text { and heating system ( } 30.4 \% \text { of the } \\
\text { answers) } \\
\text { - Information about home energy rating } \\
\text { (15.9\% of the answers) } \\
\text { - Actions made to save energy (16.1\%) }\end{array}$ & $\begin{array}{l}\text { Respondents found both aggregate and } \\
\text { disaggregate information equally } \\
\text { important. However, they should be } \\
\text { allowed to adjust the type of information } \\
\text { to be shared/known. } \\
\text { Some respondents wanted information } \\
\text { about off-peak energy tariffs while } \\
\text { others wanted to obtain real-time energy } \\
\text { feedback. }\end{array}$ \\
\hline
\end{tabular}


Table 3.Eco-feedback interface design specifications (part 2)

\begin{tabular}{|l|l|l|}
\hline & Opinions of the survey respondents & $\begin{array}{l}\text { Recommendations from the } \\
\text { researchers based on the survey } \\
\text { analysis }\end{array}$ \\
\hline $\begin{array}{l}\text { Ranking based on energy } \\
\text { consumption }\end{array}$ & $\begin{array}{l}\text { - Ranking would help promote domestic } \\
\text { pro-environmental behaviour (45\% of } \\
\text { respondents) }\end{array}$ & $\begin{array}{l}\text { Overall, there was a general } \\
\text { acceptance of ranking by the wider } \\
\text { audience. However, the ones aged } \\
\text { between 25-34 are more likely to } \\
\text { gravitate towards reward. }\end{array}$ \\
& $\begin{array}{l}\text { Ranking would help promote domestic } \\
\text { pro-environmental behaviour but only } \\
\text { when there is a reward (35.80\% of } \\
\text { respondents) } \\
\text { - Ranking would not help promote pro- } \\
\text { environmental behaviour (13.2\% of } \\
\text { respondents) }\end{array}$ & \\
\hline
\end{tabular}

\subsection{Findings of participatory workshops (Phase 3)}

This section concentrates on the design rationale of the developed community-based eco-feedback interfaces. Furthermore, it sheds light on areas where participants expressed different opinions and beliefs.

\subsubsection{Interface layout, organisation, and customisability}

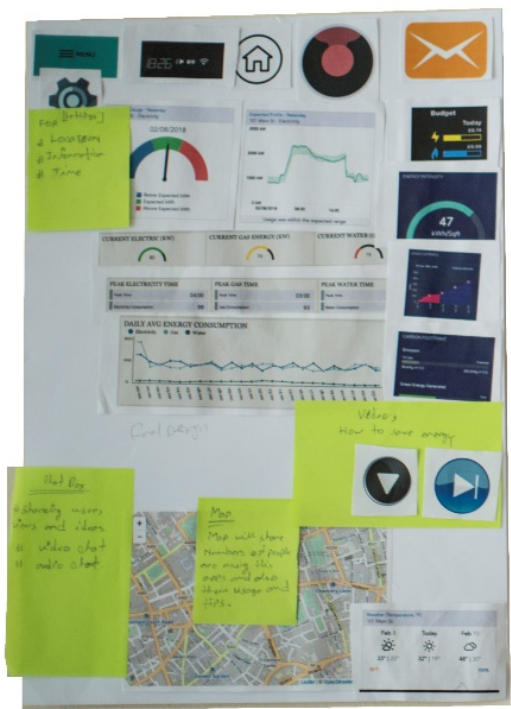

Interface 1 (workshop 1)

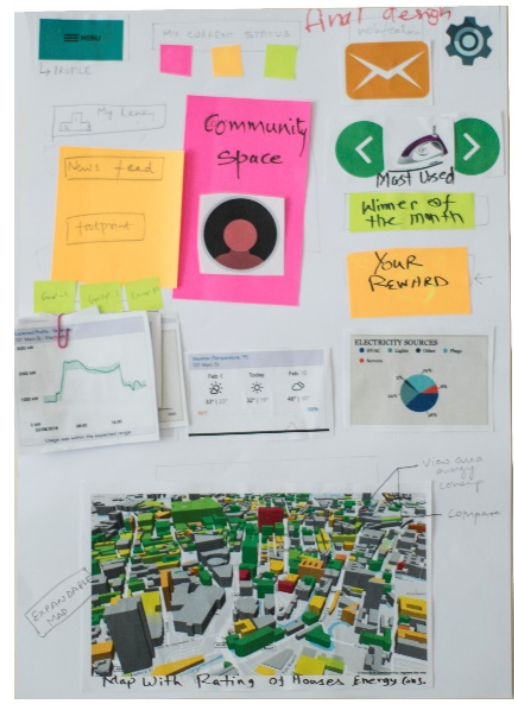

Interface 2

(Workshop 1)

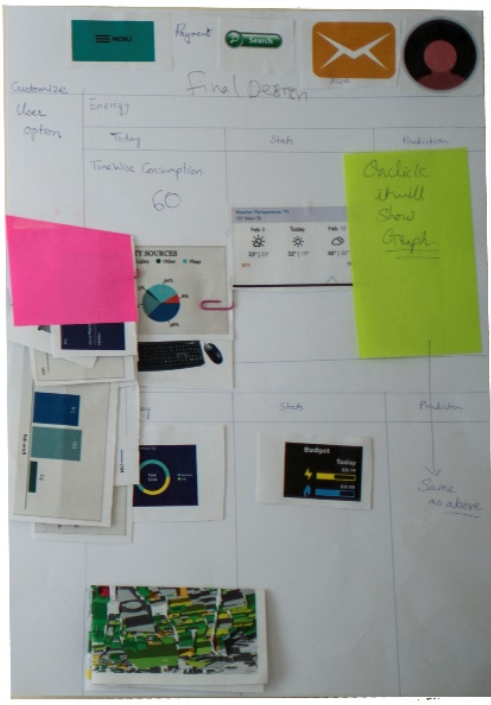

Interface 3

(Workshop 2)

Figure 20. The three designs developed by members of the community during the focus groups 
Table 4. Layout organisation of each interface design

\begin{tabular}{|c|c|c|c|c|c|c|}
\hline & $\begin{array}{l}\text { Participants } \\
\text { involved }\end{array}$ & Panel 1 & Panel 2 & Panel 3 & Panel 4 & Panel 5 \\
\hline $\begin{array}{l}\text { Interface } \\
1\end{array}$ & P1-P5 & $\begin{array}{l}\text { - Menu } \\
\text { - Notification } \\
\text { - Interface } \\
\text { preferences } \\
\text { - } \text { Digital clock }\end{array}$ & $\begin{array}{l}\text { - Current } \\
\text { aggregate energy } \\
\text { consumption } \\
\text { - Cost of aggregate } \\
\text { energy usage } \\
\text { - Comparison to } \\
\text { the average } \\
\text { energy user }\end{array}$ & $\begin{array}{l}\text { - Disaggregate energy } \\
\text { usage (historical and } \\
\text { current) }\end{array}$ & $\begin{array}{l}\text { - Eco- } \\
\text { suggestions } \\
\text { (external } \\
\text { videos and } \\
\text { links to } \\
\text { energy- } \\
\text { saving } \\
\text { support } \\
\text { schemes }\end{array}$ & $\begin{array}{l}\text { - Energy } \\
\text { performan } \\
\text { ce of the } \\
\text { neighbour } \\
\text { hood }\end{array}$ \\
\hline $\begin{array}{l}\text { Interface } \\
2\end{array}$ & P6-P10 & $\begin{array}{l}\text { - Menu } \\
\text { - Notification } \\
\text { - Interface } \\
\text { preferences } \\
\text { - My current } \\
\text { usage status }\end{array}$ & $\begin{array}{l}\text { - Community } \\
\text { interactions and } \\
\text { competition (e.g. } \\
\text { chat, newsfeed, } \\
\text { ranking, etc.) }\end{array}$ & $\begin{array}{l}\text { - Disaggregate energy } \\
\text { usage (historical and } \\
\text { current) } \\
\text { - Predicted } \\
\text { disaggregate energy } \\
\text { consumption based } \\
\text { on the weather } \\
\text { forecast. }\end{array}$ & $\begin{array}{l}\text { Energy } \\
\text { performance } \\
\text { of the } \\
\text { neighbourhoo } \\
d\end{array}$ & N/A \\
\hline $\begin{array}{l}\text { Interface } \\
3\end{array}$ & $\begin{array}{l}\text { P11-P18, } \\
\text { P9(PI), and } \\
\text { P10 (RA) }\end{array}$ & $\begin{array}{l}\text { - Menu } \\
\text { - Notifications } \\
\text { - Profile } \\
\text { - Search bar } \\
\text { - Payment } \\
\text { feature }\end{array}$ & $\begin{array}{l}\text { - Current } \\
\text { aggregate energy } \\
\text { consumption. } \\
\text { - Comparison to } \\
\text { the average } \\
\text { energy user } \\
\text { - Cost of aggregate } \\
\text { energy usage }\end{array}$ & $\begin{array}{l}\text { - Disaggregate energy } \\
\text { usage (historical and } \\
\text { current) } \\
\text { - Predicted } \\
\text { disaggregate energy } \\
\text { consumption based } \\
\text { on the weather } \\
\text { forecast }\end{array}$ & $\begin{array}{l}\text { Energy } \\
\text { performance } \\
\text { of the } \\
\text { neighbourhoo } \\
\text { d }\end{array}$ & N/A \\
\hline
\end{tabular}

Following the completion of the two focus groups, three interface designs have been developed through 12 design iterations (4 per design) as shown in figure 20. In the first workshop, the 10 participants (P1-P10) developed interfaces 1 and 2. On the other hand, the participants of workshop 2 (P11-P18 and P9\&P10) produced only interface 3 because they preferred to work in one group instead of two groups of 5 as in workshop 1 (note that close-up images of each interface are included in Appendix B).

First, $75 \%$ of the participants preferred a portrait arrangement (figure 20). Similar findings were reported by [59] who suggested that $60 \%$ of non-game based app users prefer portrait orientation. As for the interface organisations, the participants of both workshops used the design brief and the printed interface elements such as menu button, energy consumption graphs, and maps, to create the layout of their interface prototypes. As depicted in figure 20, interfaces 2 and 3 were composed of 4 panels, whereas interface 1 , had 5 panels. Nevertheless, participants who worked on interface 3 suggested that their interface should be fully customisable, "We want to give users a feeling of their own, so they can customise the interface in the way that suits them." (P1)

In interface 1, panel 1 was allocated to the menu, notification, interface preferences, and a digital clock. Panel 2; however, comprised a status panel displaying the current energy consumption and cost 
in addition to an indication of the user performance in relation to the average energy consumption in the area (e.g. low). Panel 3 contained disaggregate information about their current and historical energy consumption. Panel 4 of interface 1, encompassed external eco-suggestions in the form of videos on how to save energy and links to energy-saving support schemes. Finally, panel 5 comprised a map showing the energy usage of the area.

In contrast to the above, interface 2 contained 4 panels, where panel 1 shared similar items with the panel 1 of interfaces 1 and 3 such as allocated for menu, notifications, and interface settings. However, it included a unique feature "my current usage status" where the users get a hint on their energy performance in comparison to the average usage in the area in the form of a traffic light system (figure 20). Interestingly, the designers of interface 2 suggested that panel 2 should focus on community interactions and competition (e.g. chat, newsfeed, ranking, etc.). Like interface 1, the participants allocated panel 3 to detailed information about their historical and current usage. However, the designers of interface 2 also preferred to obtain an indication on their future energy usage based on the weather forecast. In this respect, P7 said," I read somewhere that there are algorithms that predict the energy consumption of users. I really would like to see my estimated energy usage based on the weather forecast". Finally, panel 4 was confined to showing the energy usage of the neighbourhood using maps.

From analysing table 4 and figure 20, it is evident that interface 3 share similarities with interface 2 . One of the similarities is that panel 1 of each interface includes an application menu icon, notifications button, and profile button. However, participants working on interface 3 decided to include a search bar to browse through the content of the interface quickly. Moreover, they opted for a payment feature, which will be discussed in the coming sub-sections. Similarly, panel 2 of interface 3 encompassed the aggregate energy usage of the household and an indication of their performance in relation to the average energy usage in the area. In panel 3 ; however, provides detailed information about the households present and past energy usage. In panels 2 and 3, participants (P6-P10) placed particular emphasis on knowing their predicted aggregate and disaggregate energy consumption, correspondingly. In this respect, P8 added,

"So, what we are going to give in panel 2 is the energy consumed today and then the prediction number. If I click on the predicted number in panel 2, panel 3 should show a detailed graph."

Finally, the designers of interface 3 allocated panel 4 to visualising the energy consumption of the neighbourhood on a 2D/3D map. 


\subsubsection{Interface complexity and level of information detail}

18 out of 20 participants recommended that the interfaces should be easy, enabling the user to readily and rapidly access distinct kinds of information. Their choice was ascribed to busyness and the degree of familiarity with ICT, which aligns with the findings of [52]. In this regard, a contributor (P2) added,

"I think people are quite busy and they would like something that would give them an idea on the flight and located in one place. If the interface is too complex, then it would be an obstacle for people who are not good with technology like my dad." (P2)

Similarly, 8 contributors expressed comparable opinions but proposed that the user should be in command of the level of information detail as stated the following statement,

"I think that the initial interface should be very simple but if the user would like to know more, they can click on the relevant parts to get more information." (P5)

The participant (P5) further added that users should also control the level of disaggregation in function of their preferences and energy-saving goals, "I think that all graphs should be located in one place and the user should have the option of customising what type of graphs to be displayed because we have different personal preferences and energy-saving goals." (P5)

On the one hand, the above statement contradicts many initiatives in the literature which concentrate on promoting disaggregation as a mean to motivate consumers to save energy and that pay little attention to their preferences. On the other hand, it reinforces the findings of [40] who advised that disaggregation is only more effective when participants are already motivated. Thus, there is a need for studies identifying the nature of the relationship between users' energy-saving goals and their preferences with regards the level of disaggregation.

\subsubsection{Data sharing and privacy}

Although the survey findings revealed that the majority of the surveyees preferred to share data and know about others, 3 participants expressed privacy concerns about sharing data with community members. More precisely, P13 produced the below declaration, believing that sharing energy consumption data would allow the public to begin formulating assumptions about a household lifestyle and socioeconomic status instead of concentrating on decreasing their energy use.

“To be fair, I don't like sharing. I find sharing my data with neighbours insane. Suppose that I consumed less energy than my next-door neighbours who has the same number of people and rooms. They could 
wonder why I am using less energy, is it because I cannot afford the bills, or I am staying less at home? If they do, then they miss the whole purpose of this app." (P13)

Conversely, 4 participants thought that sharing data with others generates high expectations to save energy that can cause them stress and anxiety as P9 said, "I have a reservation about people knowing that I am using high energy because that would make me feel guilty which could cause me stress and anxiety." Similar findings were also reported by [14].

\subsubsection{Relevance and type of geographical data visualisation}

Following the above discussions on data sharing, the contributors suggested that geo-location data represents the main source of privacy concerns. Indeed, the group discussions have largely focused on aspects such as the necessity of geolocation data, type of maps, and level of aggregation. For instance, 5 participants did not only question the relevance of visualising energy information on a map but also found it unnecessary. Instead, they proposed evaluating their energy performance only against their social network (below statement), which is in line with the findings of $[25,26]$.

"... sharing is fine but not to the point of clicking on the building and getting the information. I prefer to compare it against your contacts that you can add them to the application such as friends." (P8)

In contrast to the above, 8 participants believed that adopting geo-located data is indispensable for monitoring and tackling issues related to the engagement of community members in energy-saving activities as highlighted below,

"For me, it is good to see in your neighbourhood if people are interested and engaging. If no interactions, it means that the council should use some measures to tackle this." (P10)

Despite the reservations made by some of the contributors about the use of geolocation data, most groups have settled on the idea of visualising energy-related information at a lower spatial resolution than the building level such as block ${ }^{4}$ level. Finally, although the attendees had different preferences with regards using $2 \mathrm{D}$ or 3D maps, they agreed that the user should be given the option for both as discussed in the below statement,

"...If you go to a train or bus station, you can only find $2 D$, but we decided to use the $2 D$ and $3 D$ because some people might be comfortable with the $2 D$ and some other might find it easier to use the 3D." (P3)

\footnotetext{
${ }^{4}$ According to [68], a block is group of buildings bounded by four streets.
} 


\subsubsection{Community-related features and suggestions}

Despite some data sharing and comparison concerns, the majority of the groups welcomed the idea of creating a sense of competition between the community members to encourage home-energy saving. In line with the survey results, 13 contributors found ranking and colour coding beneficial. In this respect, participant (P17) advised, "Ranking can be done here on the map, you can, for example, use different colours".

While the majority of respondents recognised the importance of reward, they suggested that it should be only symbolic (non-monetary or intrinsic) to maintain a long-term engagement. This is in good agreement with many studies in the literature suggesting that monetary incentives are not necessarily superior to the non-monetary ones and could deteriorate morals [60]. One of the suggested forms of non-monetary rewards was to allow users to collect rewards points based on certain actions. Furthermore, awarding a "Green household certificate" when they have reached a certain number of points. Other suggestions included the announcement of the winner of the month in the newsfeed.

Although the attendees were motivated about reducing their carbon footprint in various ways (e.g. self-evaluation and social comparisons), the authors felt that community interaction related features have not been the central focus in their design suggestions. More precisely, the contributors focused more on the visualisation of their energy-related information than on the design of community basedfeatures. Indeed, the majority of their community-related suggestions revolved around community messaging boards and newsfeed with no consideration of features around action sharing and community goal setting. For example, participant P13 mentioned,

"... Now, if you want to chat with any one of them to share information or to communicate on how you can save more energy, the user could click on a building with a green colour and have a chat with that person." (P13)

Part of this issue could be associated with the present forms of social media dominating the participants' perception of community interaction. Another contributing factor is the dominance of in-home smart meter displays, which solely focus on visualising the energy consumption of a given household. However, since there is not enough scientific evidence to reinforce the above hypothesises, more research is needed in that respect.

\subsubsection{Integration with other applications}


In response to the busyness of the households and the impact on engagement in energy-saving activities, 10 participants (P11-P18, PA and RI) recommended developing a multi-purpose Ecofeedback app by integrating features from third-party applications and websites. In this respect, participant P15 mentioned, "The other part that I am trying to convey in this app is not to use many apps but to use the only one which can serve for multi-purposes". (P15)

The groups' suggestions revolved around linking the developed app with the energy suppliers' ones to pay their energy bills and/or to check their energy usage. Furthermore, they focused on hosting some features from websites that compare and suggest various energy tariffs such as U-Switch. Again, the advantages of multi-purpose applications over the single-purpose ones is a well-documented area of research [61], which widely acknowledges that multi-purpose applications are customisable offering a high degree of simplicity. Furthermore, they are ideal for solving multiple problems efficiently and cost-effectively. For those reasons, there will be a consideration for integrating thirdparty applications in the developed community-based Eco-feedback tool.

\section{Implication on the design of community-based Eco-feedback interface (Phase 4)}

Tables 5, 6, and 7 represent the summary of our research findings. Moreover, highlight their implications on the final design of the community-based Eco-feedback interface, which is addressed in more details in the subsequent sub-sections.

\subsection{General layout and organisation}

Figures 21 depicts the developed community-based eco-feedback interface on the initial launch, whereas figure 22 illustrates the full interface with panels 3 and 4 expended. As suggested by most of the community members, the layout of the community-based Eco-feedback interface will be composed of 4 panels. However, in response to suggestions from the community (see section 4.3.2), only panels 1 and 2 appear on the initial application launch (see figure 21). This means that the users need to expand panels 3 and 4 to obtain more information on disaggregated energy usage, energy saving suggestions, and consumption in the area. 


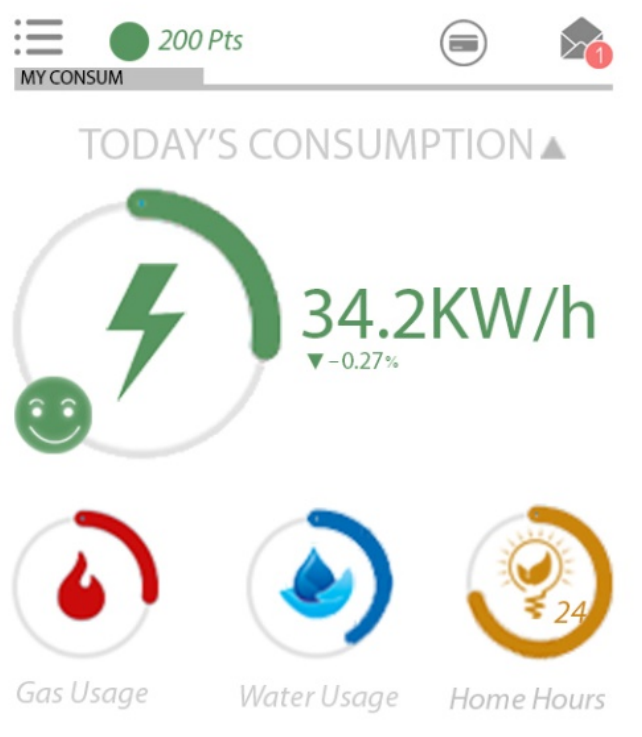

COMMUNITY SPACE

Nottinghamshire $\odot$ Sneinton

DETAILED CONSUM $\triangle$ COMMUMAP

Figure 21. Community-based user-interface on the initial launch

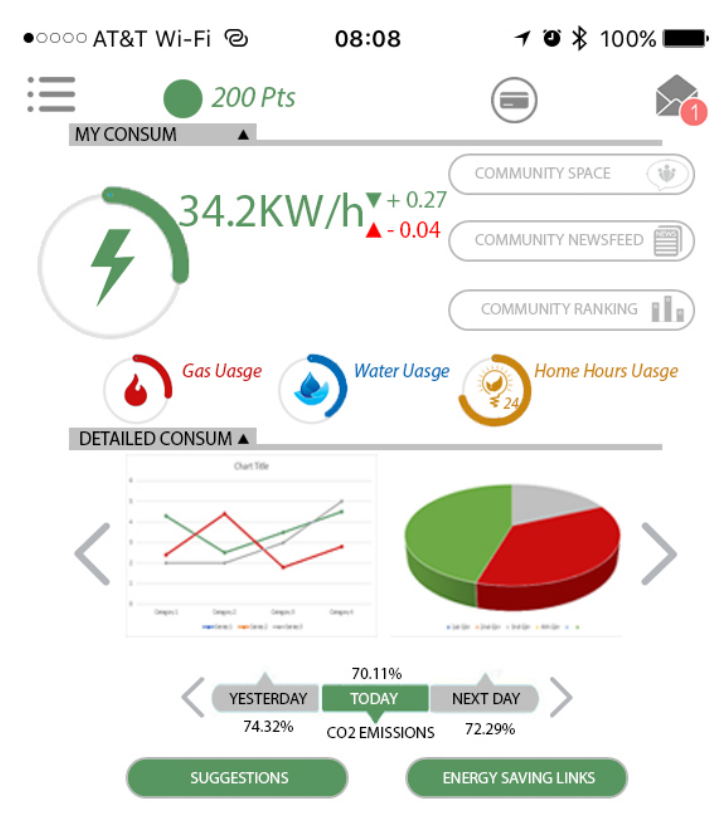

WEATHERTODAY

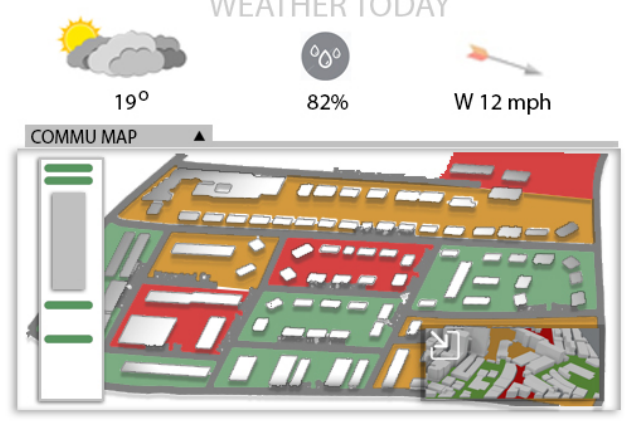

Figure 22. The full version of Communitybased user-interface with panels 3 and 4 expanded.

In both the initial and full versions, panel 1 comprises features such as menu and settings in addition to my current consumption status, reward points, and notifications. Conversely, panel 2, in turn, consists of two areas (figure 21). The first one provides users with aggregate information about their energy usage and compares it to the average consumption in the area (e.g. $+10 \% /$ smiley emoticons). The second area; however, encompasses a community space which was particularly designed to promote community interactions and engagement in energy-saving activities. In particular, users can share their energy-saving actions and know about the ones of community members who, in turn, are ranked based on their energy consumption (see figure 23). To get suggestions and/ or find out more about the saving measures of others, it is possible to start a discussion with them in the community interaction space located below the community ranking/saving area (figure 23). The community space is also equipped with a newsfeed widget located at the top, which offers community members regular updates on different energy saving matters. 
Panel 3, which only appears in the full version, offers users the possibility to consult their disaggregated energy consumption related information such as energy graphs, weather widget, and carbon footprint. In addition to that, it provides them with suggestions and links to energy savings including energy-saving support schemes. Finally, panel 4 of the expended version is equipped with a 2D and 3D maps visualising the energy consumption of the area (see figure 22).

$\bullet \circ 000$ AT\&T Wi-Fi 巳

08:08

ฯ * 100\%

$:=200$ Pts

COMMUNITY SPACE
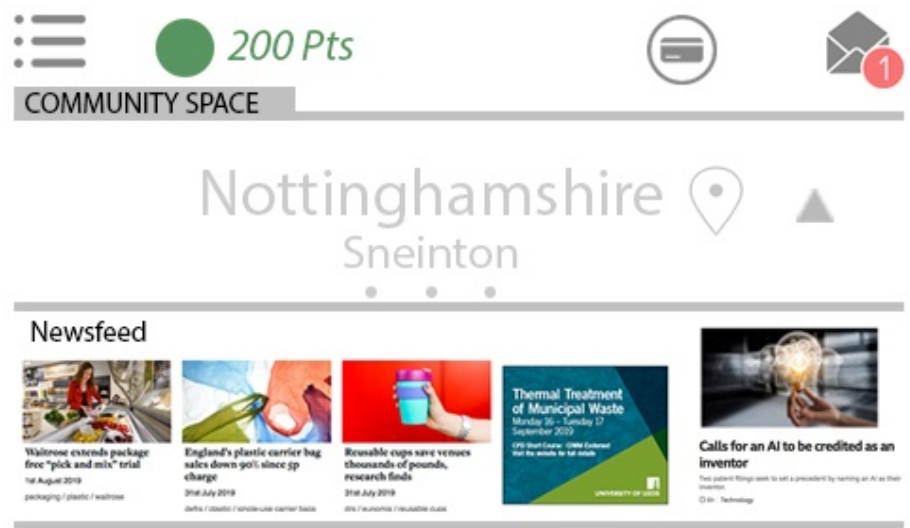

My Saving Actions

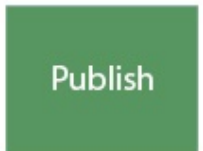

\begin{tabular}{|ll|}
\hline Action 1 & Add a Description \\
\hline Action 2 & Add a Description \\
\hline Action 3 & A Add a Description \\
\hline
\end{tabular}

Community Actions/ Ranking
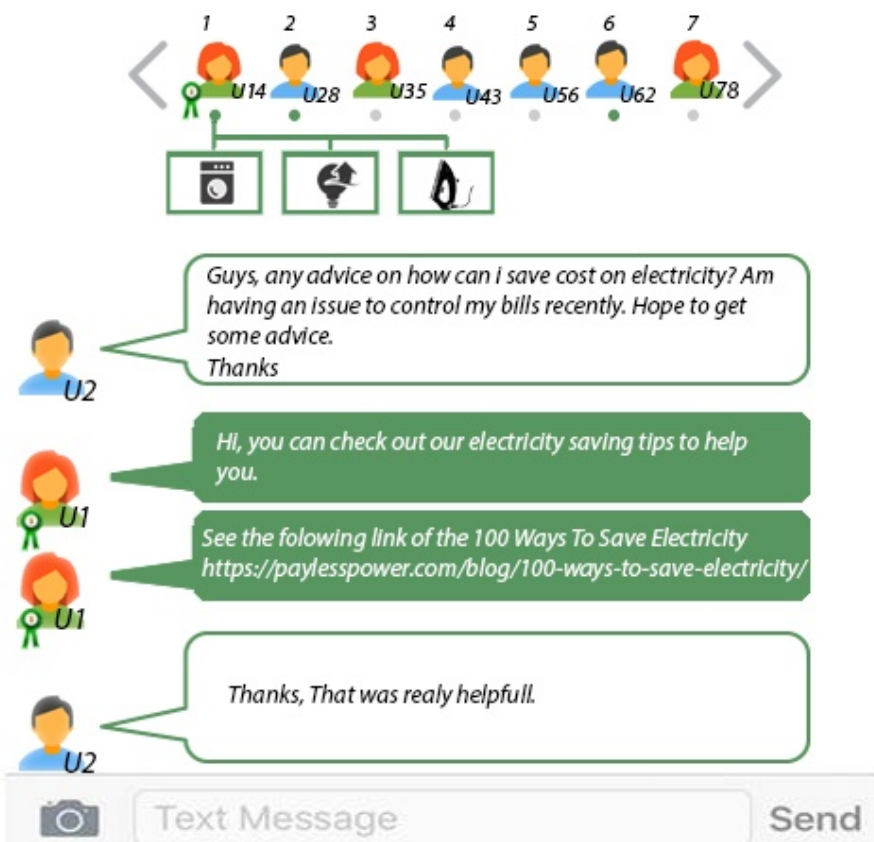

Figure 23. The Community space of the developed eco-feedback interface 


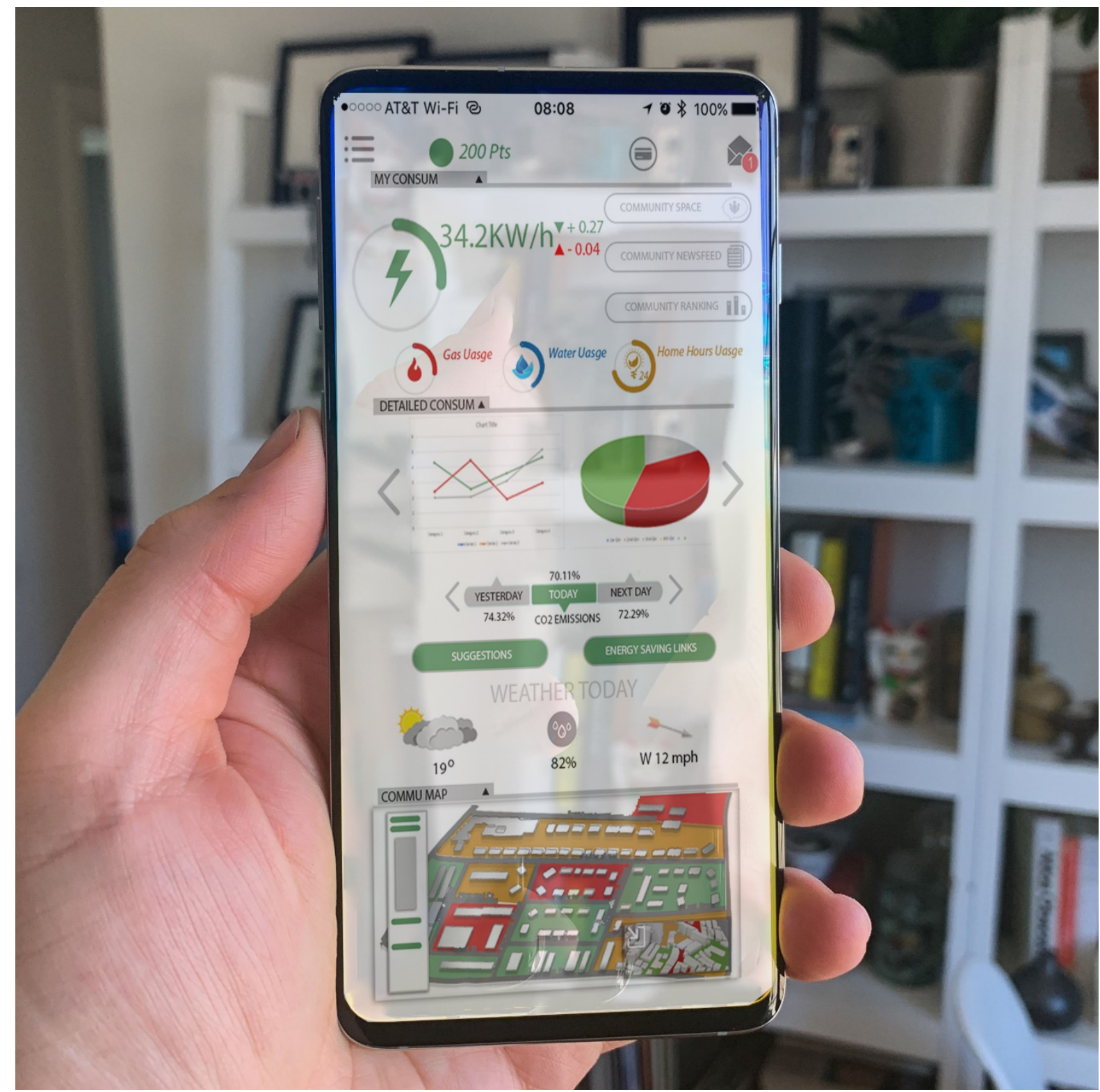

Figure 24. The full community-based eco-feedback application visualised on a smartphone

\subsection{All other features}

Tables 6 and 7 (below) summarise the non-layout suggestions regarding the community-based Ecofeedback interface. Moreover, they outline the list of actions that have been taken to finalise its development.

First, the mapping of energy consumption related data onto the 2D/3D maps in panel 4 is performed at a rough spatial resolution (Block level) instead of the building level. This is mainly to protect the participants' privacy while reducing intrusiveness, which helps community members concentrate 
solely on energy-saving activities. Similarly, to address the feeling of guilt or being under pressure as a result of consuming high energy figures than others, all users will bear a pseudo name when interacting and/ or sharing data with other community members. Furthermore, they possess the full control of their social network where users can invite/ add members and determine the type of information to be shared/ known.

Since they were widely accepted by the community members (see 4.3.5), competition-related features (e.g. ranking) and non-monetary reward mechanisms such as green certificate and winner of the month, have been implemented in the developed interface. The green certificate is awarded upon reaching certain rewards points. These, in turn, are earned based on performing specific actions such as reporting energy-saving activities, accessing the suggestions, interacting with the community, and meeting saving goals. Members with a green certificate are identified by small medal next to their pseudo name (figure 23). Apart from that, at the end of each month, there will be an announcement of the winner of the month for consuming the lowest energy figure in the area.

Finally, in response to proposals to develop a multi-purpose application as discussed in 4.3.6, a payment feature has been integrated where users can directly pay their utility bills (figure 11). However, other features from third party websites and apps such as tariff comparison have not been considered in this release. This is because switching to cheaper tariffs is sometimes associated with an increase in energy usage [62], which contradicts the purpose of the developed community-based eco-feedback app. Nevertheless, more research is needed to help identify methods for incorporating such a feature while maintaining good engagement levels in energy-saving activities. 


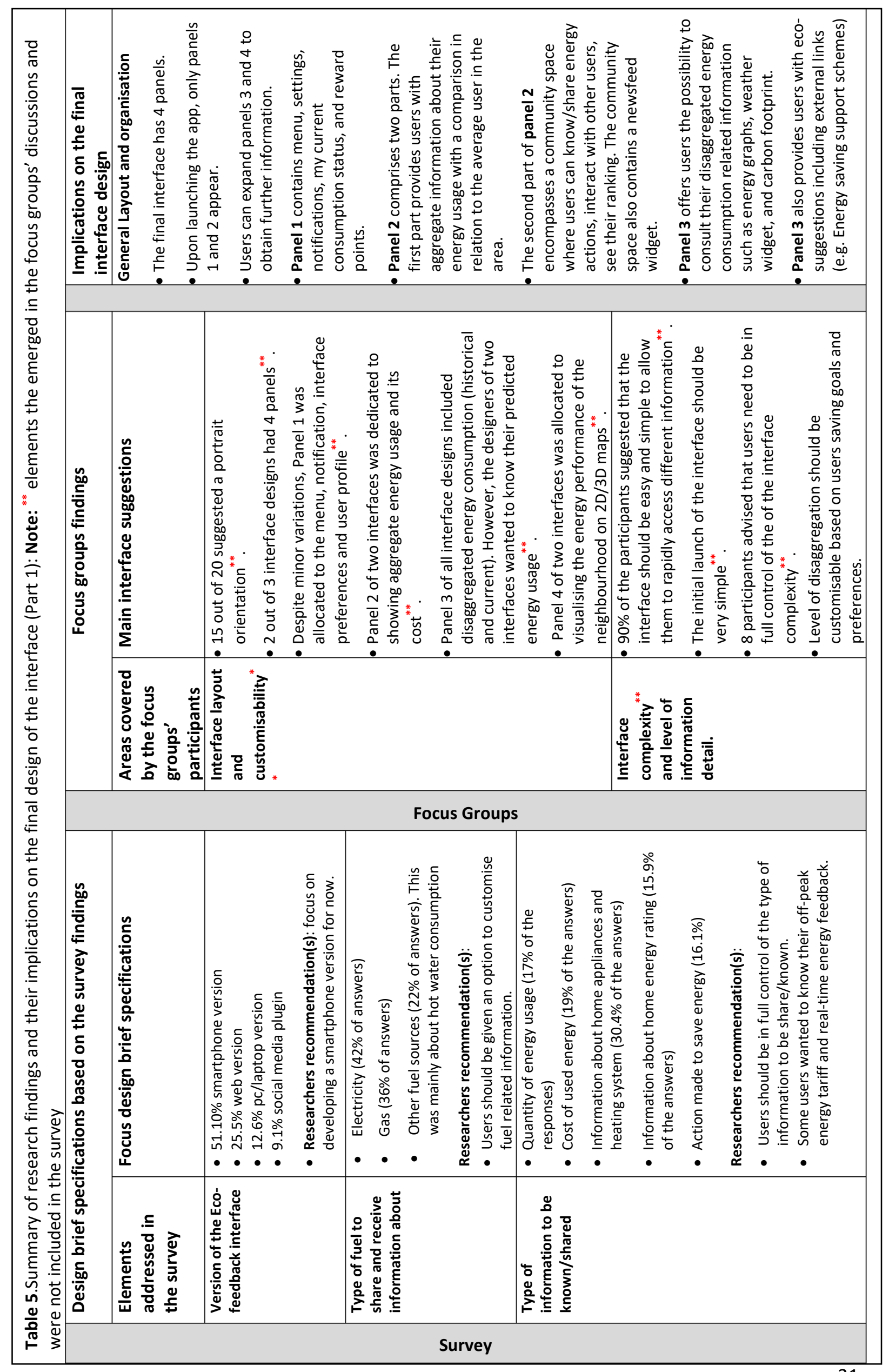




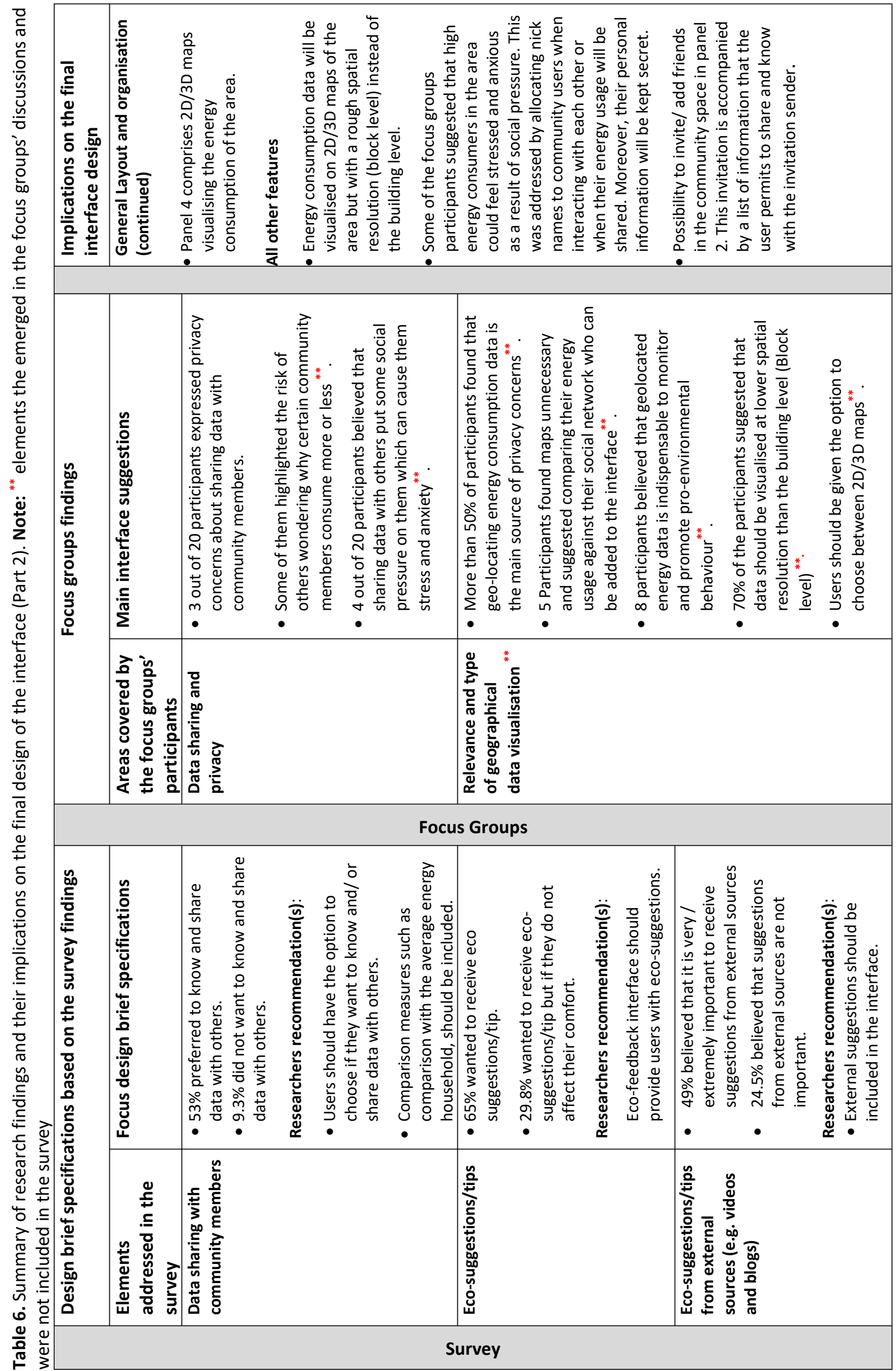




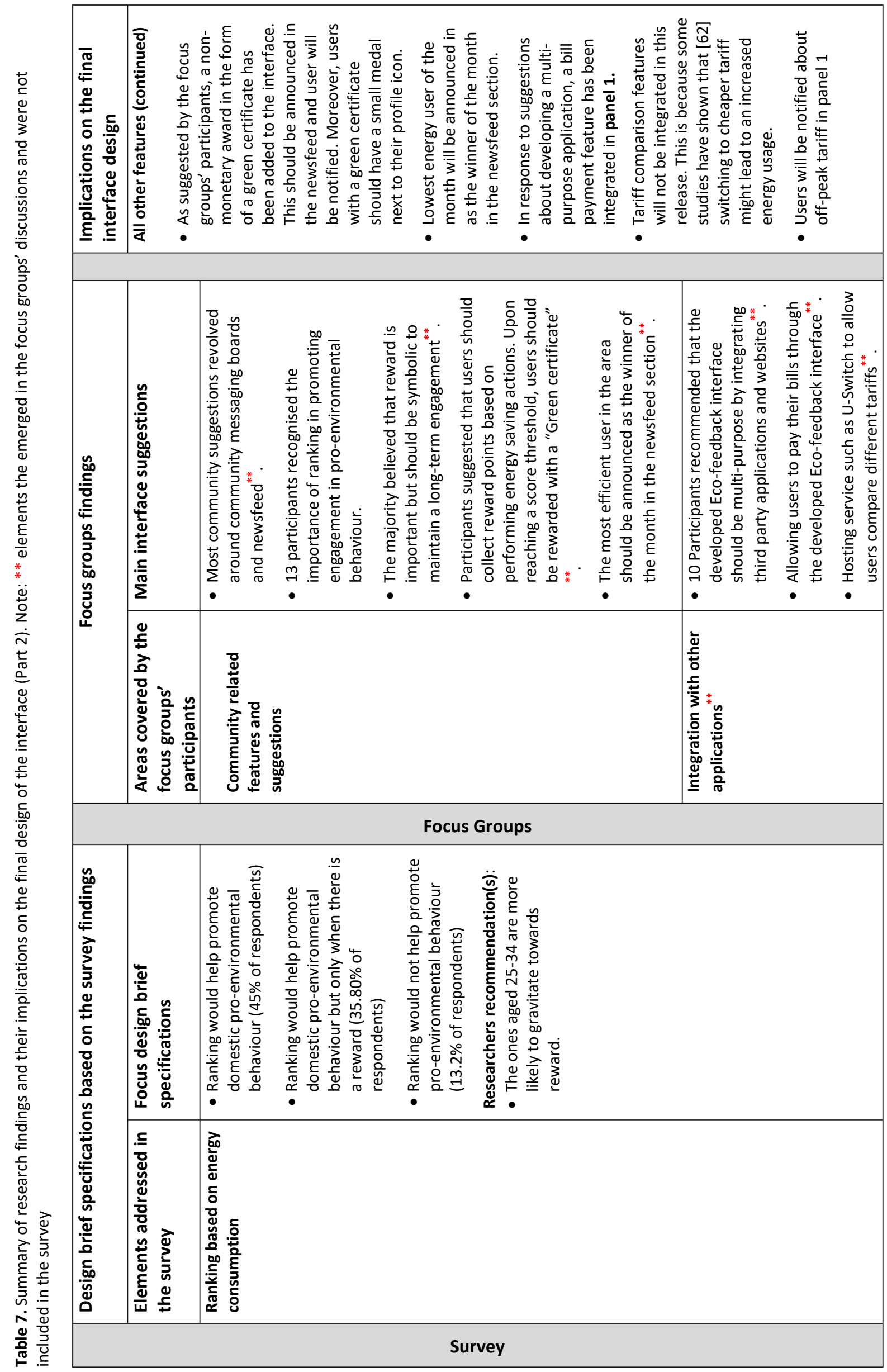




\section{Conclusions and Future Work}

Our analysis of existing community-based Eco-feedback applications found that there is a lack of codesign (participatory) initiatives during their design stage. Indeed, much of the current conversations on community engagement in the development of Eco-feedback systems is limited to testing ecofeedback systems and providing suggestions during the implementation stages to assist their improvement.

To address the research gap and explore the potential of community engagement in the design process of eco-feedback applications, this research aimed to utilise a participatory (co-design) approach to design an accessible community based eco-feedback interface in collaboration with Nottingham city community members and energy experts. First, we conducted an online survey questionnaire with 151 participants with distinct socio-economic characteristics and environmental knowledge to determine their preferences about the various aspects of the developed eco-feedback interface. These aspects comprised: familiarity with ICT, technology preferences, privacy, social interaction, and type of feedback. Secondly, the survey findings have been used to develop a design brief containing the eco-feedback interface specifications. The design brief was used by 20 participants including the authors, energy experts, and community members living in Nottingham to collaboratively develop interface prototypes through two participatory focus groups. Finally, premised on the interface prototypes and suggestions/ preferences that emerged during the focus groups, the researchers produced a consensual version of the community based eco-feedback interface.

Although generalisations are limited and cautious due to the demographics of the sample, the analysis of the survey findings permitted to gain insights into themes (e.g. privacy) whose influence on the engagement in pro-environmental behaviour is still debated in the literature. As depicted in tables 5, 6 , and 7 , the analysis of the survey questionnaire advised that respondents, regardless of their socioeconomic profile, attributed the lack of engagement in home energy-saving activities to the paucity of information and busyness to a lesser extent. Furthermore, they recognised the importance of developing eco-feedback applications that contain social interaction features such as ranking in promoting pro-environmental behaviour. As for their preferences, most respondents preferred a smartphone version and sought eco-suggestions/ tips including the ones from external sources such as videos and websites. They also suggested obtaining information about their electricity, gas, and/ or hot water consumption and found both aggregate and disaggregate information equally important. Moreover, the majority showed no reservation about sharing their information anonymously with 
other community members. However, to allow for a transparent and democratic participation process, users should be in full control of the types of information to be shared/ known and its level of disaggregation.

While the participatory focus groups permitted the development of three interface design proposals, the adoption of this participatory (co-design) approach was invaluable to this research. First, the interaction between different participants during the focus groups permitted the generation of new ideas and insights that were not included in the survey questionnaire and could push the use of ecofeedback applications "beyond providing feedback". Examples of the themes that emerged are 1interface complexity, 2-integration of third-party applications (e.g. bills -payment and integration of tariff comparison websites such as U-Switch), 3-community related features including reward points, green certificate, and winner of the month. Second, the participants have not only demonstrated a high level of awareness to potential ethical issues that could arise from community interactions (e.g. social pressure) but also came up with practical solutions which align with the findings of [63]. Mapping energy-related data at the block level instead of the building level is an example of the suggested solutions.

In response to the survey and focus groups findings, the final interface was designed in a way that offers some degree of flexibility, customisation, and simplicity to the users depending on their preferences. In this respect, the interface starts with only two panels containing minimal information on their aggregate electricity, gas, and/or water current usage with an indication of users' performance in relation to the average usage of the area. To gain deeper levels of information (e.g. disaggregate energy usage or predicted energy consumption), interact with the community, and/ or consult the energy performance of the neighbourhood, users need to expand panels 3 and/or 4 (figure 21-24). To address privacy concerns and social pressure expressed by the participants, users were given control over what type of information to be known/shared with other community members.

Despite the time and efforts dedicated to the development of this community-based eco-feedback interface, there is more to be done. This is because some of the aspects require further improvement whilst others, need to be studied in more depth. Firstly, although the community were able to develop the interface layout and main features, the time constraints of this study prevented them from investigating the design of individual entities such as visualisation of feedback. While there is a wide range of visualisation techniques to aid informed decision-making, research has shown that the use of inappropriate eco-visualisation techniques could lower the engagement levels in energy-saving 
activities $[64,65]$. Therefore, studying the effectiveness of different visualisation techniques is among our future research priorities. Another area that requires attention in the near future is the study of the relationship between users' level of motivation for energy-saving and their preferences towards the level of disaggregation. This will in turn help establish energy profiles that govern the level of disaggregation and the complexity of meeting energy-saving goals depending on the user motivations and experience with home energy saving. Finally, upon the completion of the planned research, the interface has, in turn, to be implemented and tested in a residential setting to help improve its performance and evaluate some features. In particular, this will enable the assessment of the impact of third-party applications such as tariff comparison on the level of community engagement in energysaving activities. Initial signs are positive though that these collaborative community initiatives have the potential to address some of the challenges inherent in feedback and increase the acceptance, adoption and impact of behaviour change led solutions.

\section{Acknowledgement}

This work has been funded by a Nottingham Trent University Sustainable Futures grant (RD 077). A special thanks goes to Nottingham Energy Partnership (NEP) and for reviewers who gave invaluable feedback during the writing process.

\section{References}

[1] BEIS, ENERGY CONSUMPTION IN THE UK, 2018 https://assets.publishing.service.gov.uk/government/uploads/system/uploads/attachment_data/file/7 29317/Energy_Consumption_in_the_UK_ECUK__2018.pdf (accessed March 17, 2019).

[2] A. Paone, J.-P. Bacher, The impact of building occupant behavior on energy efficiency and methods to influence it: A review of the state of the art, Energies. 11 (2018) 953.

[3] M.A. Andor, K.M. Fels, Behavioral economics and energy conservation-a systematic review of nonprice interventions and their causal effects, Ecol. Econ. 148 (2018) 178-210.

[4] L. Steg, C. Vlek, Encouraging pro-environmental behaviour: An integrative review and research agenda, J. Environ. Psychol. 29 (2009) 309-317.

[5] W. Abrahamse, E. Matthies, Informational strategies to promote pro-environmental behaviour: Changing knowledge, awareness and attitudes, Environ. Psychol. An Introd. (2012) 223-232.

[6] W. Abrahamse, Encouraging Pro-environmental Behaviour: What Works, What Doesn't, and why Academic Press, 2019.

[7] G. Ma, J. Lin, N. Li, J. Zhou, Cross-cultural assessment of the effectiveness of eco-feedback in building energy conservation, Energy Build. 134 (2017) 329-338.

[8] G. Peschiera, J.E. Taylor, The impact of peer network position on electricity consumption in building occupant networks utilizing energy feedback systems, Energy Build. 49 (2012) 584-590. 
[9] J.E. Petersen, V. Shunturov, K. Janda, G. Platt, K. Weinberger, Dormitory residents reduce electricity consumption when exposed to real-time visual feedback and incentives, Int. J. Sustain. High. Educ. 8 (2007) 16-33.

[10] I. Vassileva, M. Odlare, F. Wallin, E. Dahlquist, The impact of consumers' feedback preferences on domestic electricity consumption, Appl. Energy. (2012).

https://doi.org/10.1016/j.apenergy.2011.12.067.

[11] A. Grønhøj, J. Thøgersen, Feedback on household electricity consumption: Learning and social influence processes, Int. J. Consum. Stud. (2011). https://doi.org/10.1111/j.1470-6431.2010.00967.x.

[12] IARU, BEHAVIOUR CHANGE INTERVENTIONS FOR REDUCED ENERGY USE Best Practices for Universities, 2017. https://www.sustainabilityexchange.ac.uk/files/energy_behavior_case_study_v2__university_of_oxford.pdf (accessed June 6, 2019).

[13] R. Gupta, L. Barnfield, M. Gregg, Exploring innovative community and household energy feedback approaches, Build. Res. Inf. 46 (2018) 284-299. https://doi.org/10.1080/09613218.2017.1356130.

[14] T.R. Dillahunt, J. Mankoff, Understanding factors of successful engagement around energy consumption between and among households, in: Proc. 17th ACM Conf. Comput. Support. Coop. Work Soc. Comput., ACM, 2014: pp. 1246-1257.

[15] M. Steen, Co-design as a process of joint inquiry and imagination, Des. Issues. 29 (2013) 16-28.

[16] C. Spinuzzi, The methodology of participatory design, Tech. Commun. 52 (2005) 163-174.

[17] R. Bull, K.B. Janda, Beyond feedback: introducing the 'engagement gap'in organizational energy management, Build. Res. Inf. 46 (2018) 300-315.

[18] T. Hargreaves, Beyond energy feedback, Build. Res. Inf. 46 (2018) 332-342.

[19] S.R. Arnstein, A ladder of citizen participation, J. Am. Inst. Plann. 35 (1969) 216-224.

[20] NTU, REMOURBAN City Demonstrator Project | Nottingham Trent University, (2014). https://www.ntu.ac.uk/research/groups-and-centres/projects/remourban-city-demonstrator-project (accessed May 21, 2017).

[21] N. Mogles, J. Padget, E. Gabe-Thomas, I. Walker, J. Lee, A computational model for designing energy behaviour change interventions, User Model. User-Adapt. Interact. 28 (2018) 1-34.

[22] A. Khosrowpour, R.K. Jain, J.E. Taylor, G. Peschiera, J. Chen, R. Gulbinas, A review of occupant energy feedback research: Opportunities for methodological fusion at the intersection of experimentation, analytics, surveys and simulation, Appl. Energy. 218 (2018) 304-316. https://doi.org/10.1016/j.apenergy.2018.02.148.

[23] A. Sanguinetti, K. Dombrovski, S. Sikand, Information, timing, and display: A design-behavior framework for improving the effectiveness of eco-feedback, Energy Res. Soc. Sci. 39 (2018) 55-68. https://doi.org/10.1016/J.ERSS.2017.10.001.

[24] Y.T. Shen, P.C. Chen, T.S. Jeng, Design and evaluation of eco-feedback interfaces to support locationbased services for individual energy awareness and conservation, in: Int. Conf. Human-Computer Interact., Springer, 2013: pp. 132-140.

[25] K. Sernhed, J. Pyrko, J. Abaravicius, Bill me this way!-customer preferences regarding electricity bills in Sweden, Proc. 2003 Summer Study Eur. Counc. an Energy Effic. Econ. (2003) 1147-1150.

[26] R. Gasser, D. Brodbeck, M. Degen, J. Luthiger, R. Wyss, S. Reichlin, Persuasiveness of a mobile lifestyle coaching application using social facilitation, in: Int. Conf. Persuas. Technol., Springer, 2006: pp. 27-38.

[27] V. Edward, C.M. Jones, A review of energy reduction competitions. what have we learned?, (2015).

[28] F. van Horen, A. van der Wal, A. Grinstein, Green, greener, greenest: Can competition increase sustainable behavior?, J. Environ. Psychol. 59 (2018) 16-25. 
https://doi.org/10.1016/J.JENVP.2018.08.007.

[29] R.K. Jain, R. Gulbinas, J.E. Taylor, P.J. Culligan, Can social influence drive energy savings? Detecting the impact of social influence on the energy consumption behavior of networked users exposed to normative eco-feedback, Energy Build. 66 (2013) 119-127.

[30] P. Petkov, F. Köbler, M. Foth, H. Krcmar, Motivating domestic energy conservation through comparative, community-based feedback in mobile and social media, in: Proc. 5th Int. Conf. Communities Technol., ACM, 2011: pp. 21-30.

[31] J. Froehlich, L. Findlater, M. Ostergren, S. Ramanathan, J. Peterson, I. Wragg, E. Larson, F. Fu, M. Bai, S. Patel, The design and evaluation of prototype eco-feedback displays for fixture-level water usage data, in: Proc. SIGCHI Conf. Hum. Factors Comput. Syst., ACM, 2012: pp. 2367-2376.

[32] G. Alberts, Z. Gurguc, P. Koutroumpis, R. Martin, M. Muûls, T. Napp, Competition and norms: A selfdefeating combination?, Energy Policy. 96 (2016) 504-523.

[33] BritishGas, Smart Meter Maze Game - British Gas, (2018). https://www.britishgas.co.uk/thesource/your-home/smarter-living/Smart-meter-maze-game (accessed June 12, 2019).

[34] J. Mankoff, S.R. Fussell, T. Dillahunt, R. Glaves, C. Grevet, M. Johnson, D. Matthews, H.S. Matthews, R. McGuire, R. Thompson, StepGreen. org: Increasing energy saving behaviors via social networks, in: Fourth Int. AAAI Conf. Weblogs Soc. Media, 2010.

[35] O-Power, Ask Less, Get More: The Behavioral Science of Limiting User Behavior User Experience Magazine, (2015). http://uxpamagazine.org/ask-less-get-more/ (accessed June 12, 2019).

[36] A. Kamilaris, A. Pitsillides, C. Fidas, Social Electricity: a case study on users perceptions in using green ICT social applications, Int. J. Environ. Sustain. Dev. 15 (2016) 67-88.

[37] D.N. Crowley, E. Curry, J.G. Breslin, Leveraging social media and IOT to bootstrap smart environments, in: Big Data Internet Things A Roadmap Smart Environ., Springer, 2014: pp. 379-399.

[38] R. Bull, M. Lemon, D. Everitt, G. Stuart, Moving beyond feedback: Energy behaviour and local engagement in the United Kingdom, Energy Res. Soc. Sci. 8 (2015) 32-40.

[39] H.A. He, S. Greenberg, E.M. Huang, One size does not fit all: applying the transtheoretical model to energy feedback technology design, in: Proc. SIGCHI Conf. Hum. Factors Comput. Syst., ACM, 2010: pp. 927-936.

[40] J. Kelly, W. Knottenbelt, Does disaggregated electricity feedback reduce domestic electricity consumption? A systematic review of the literature, ArXiv Prepr. ArXiv1605.00962. (2016).

[41] M.R. Herrmann, D.P. Brumby, T. Oreszczyn, X.M.P. Gilbert, Does data visualization affect users' understanding of electricity consumption?, Build. Res. Inf. 46 (2018) 238-250. https://doi.org/10.1080/09613218.2017.1356164.

[42] D. Council, Double diamond design process [online] 2015.[Accessed: 10 January 2017], (2015).

[43] S. Hawken, H. Han, C. Pettit, Open cities, open data : collaborative cities in the information era, (2020). http://search.ebscohost.com/login.aspx?direct=true\&scope=site\&db=nlebk\&db=nlabk\&AN=2258642.

[44] M.M. E. Moula, J. Maula, M. Hamdy, T. Fang, N. Jung, R. Lahdelma, Researching social acceptability of renewable energy technologies in Finland, Int. J. Sustain. Built Environ. (2013). https://doi.org/10.1016/j.ijsbe.2013.10.001.

[45] R.A. Stebbins, Exploratory research in the social sciences, Sage, 2001.

[46] M.Q. Patton, Qualitative research, Encycl. Stat. Behav. Sci. (2005).

[47] Jisc, Take part in research fast, free and ethically! - Call For Participants, (2019). https://www.callforparticipants.com/ (accessed November 12, 2019).

[48] S. Dow, B. Maclntyre, J. Lee, C. Oezbek, J.D. Bolter, M. Gandy, Wizard of Oz support throughout an 
iterative design process, IEEE Pervasive Comput. 4 (2005) 18-26.

[49] B.K. Sovacool, J. Axsen, S. Sorrell, Promoting novelty, rigor, and style in energy social science: towards codes of practice for appropriate methods and research design, Energy Res. Soc. Sci. 45 (2018) 12-42.

[50] S. Tsoka, K. Tsikaloudaki, T. Theodosiou, A. Dugue, Rethinking user based innovation: Assessing public and professional perceptions of energy efficient building facades in Greece, Italy and Spain, Energy Res. Soc. Sci. (2018). https://doi.org/10.1016/j.erss.2018.02.009.

[51] G. Liobikienè, M.S. Poškus, The Importance of Environmental Knowledge for Private and Public Sphere Pro-Environmental Behavior: Modifying the Value-Belief-Norm Theory, Sustainability. (2019). https://doi.org/10.3390/su11123324.

[52] S. Makonin, M.H. Kashani, L. Bartram, The affect of lifestyle factors on eco-visualization design, ArXiv Prepr. ArXiv1405.5263. (2014).

[53] A. Kenis, Ecological citizenship and democracy: Communitarian versus agonistic perspectives, Env. Polit. (2016). https://doi.org/10.1080/09644016.2016.1203524.

[54] M.J. Coleman, K.N. Irvine, M. Lemon, L. Shao, Promoting behaviour change through personalized energy feedback in offices, Build. Res. Inf. 41 (2013) 637-651.

[55] B. Mills, J. Schleich, Residential energy-efficient technology adoption, energy conservation, knowledge, and attitudes: An analysis of European countries, Energy Policy. 49 (2012) 616-628.

[56] L. Pereira, F. Quintal, M. Barreto, N.J. Nunes, Understanding the limitations of eco-feedback: a oneyear long-term study, in: Int. Work. Human-Computer Interact. Knowl. Discov. Complex, Unstructured, Big Data, Springer, 2013: pp. 237-255.

[57] Citizensadvice, False Economy: Missed opportunities and failures in the "time of use" tariff market, 2019.

[58] MHCLG, Neighbourhood planning - GOV.UK, 2019. https://www.gov.uk/guidance/neighbourhoodplanning--2 (accessed June 18, 2019).

[59] J. Clark, Designing for Touch, A Book Apart, 2015. https://books.google.co.uk/books?id=IAEVjwEACAAJ.

[60] V. Tiefenbeck, A. Wörner, S. Schöb, E. Fleisch, T. Staake, Real-time feedback promotes energy conservation in the absence of volunteer selection bias and monetary incentives, Nat. Energy. 4 (2019) 35-41. https://doi.org/10.1038/s41560-018-0282-1.

[61] A.J. Smith, General Purpose Software, in: Comput. Quant. Surv., Macmillan Education UK, London, 1989: pp. 80-92. https://doi.org/10.1007/978-1-349-10857-2_5.

[62] W. Matar, A look at the response of households to time-of-use electricity pricing in Saudi Arabia and its impact on the wider economy, Energy Strateg. Rev. 16 (2017) 13-23. https://doi.org/10.1016/J.ESR.2017.02.002.

[63] B.K. Sovacool, What are we doing here? Analyzing fifteen years of energy scholarship and proposing a social science research agenda, Energy Res. Soc. Sci. 1 (2014) 1-29.

[64] T. Hargreaves, M. Nye, J. Burgess, Making energy visible: A qualitative field study of how householders interact with feedback from smart energy monitors, Energy Policy. 38 (2010) 6111-6119. https://doi.org/10.1016/J.ENPOL.2010.05.068.

[65] S. Darby, The effectiveness of feedback on energy consumption, A Rev. DEFRA Lit. Metering, Billing Direct Displays. 486 (2006) 2006.

[66] G. Ritzer, The Blackwell encyclopedia of sociology, Blackwell Publishing New York, NY, USA, 2007.

[67] Remourban, City overview, (2017). http://www.remourban.eu/Cities/LighthouseCities/Nottingham/City-Overview.kl (accessed May 21, 2017).

[68] Cabe, THE COUNCILLOR'S GUIDE TO URBAN DESIGN, 2003. 


\section{Appendix A}

\section{Section 1: Environmental Knowledge}

1. How is your knowledge about home energy saving?

Not knowledgeable about

Somewhat knowledgeable about

Knowledgeable about

Very knowledgeable about

2. Do you feel responsible for reducing your home energy consumption?
Y Yes
(C) No
Not sure
Other

3. Based on your experience, why people don't engage in pro-environmental behaviour such as reducing their home energy consumption? (Check all that apply)
Ineffective tools of communication
Lack of information about energy saving
No real benefit for individuals
$\lceil\quad$ Time and availability
Not worried about their bills
$\Gamma$ Other

4. What actions have you made recently to save energy?

Type your answer here 
4. How comfortable are you with technology such as computers and smartphones?
Very comfortable
Somewhat comfortable
Somewhat not comfortable
Not quite comfortable
Other

5. How important do you think is to develop applications and devices that assist with energy savings?
Not important
Less important
Somewhat important
Very important
Extremely important
Other

6. We are developing a software application o help the community reduce their home energy consumption. What would be your preferred software version? (Check all that apply)

$\Gamma$ Website version

$\lceil\quad$ Integrated into Social media such as Facebook and Twitter

$\ulcorner$ Smartphone application

Г PC/Laptop application

$\Gamma$ Other 
7. What are your thoughts about sharing energy consumption data anonymously with the community members? (please note that your personal information will NOT be shared)

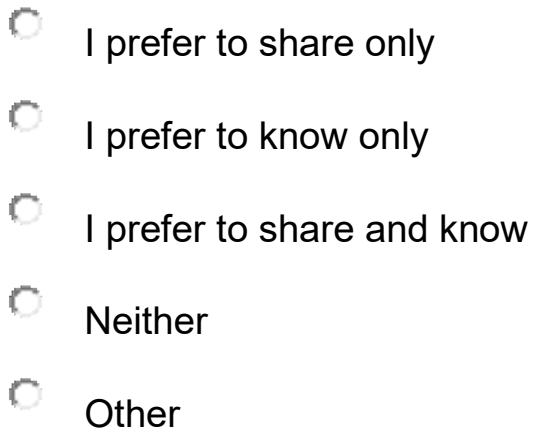

8. The software that we are developing can give you suggestions on home energy saving. Would you consider those suggestions to save your home energy consumption?

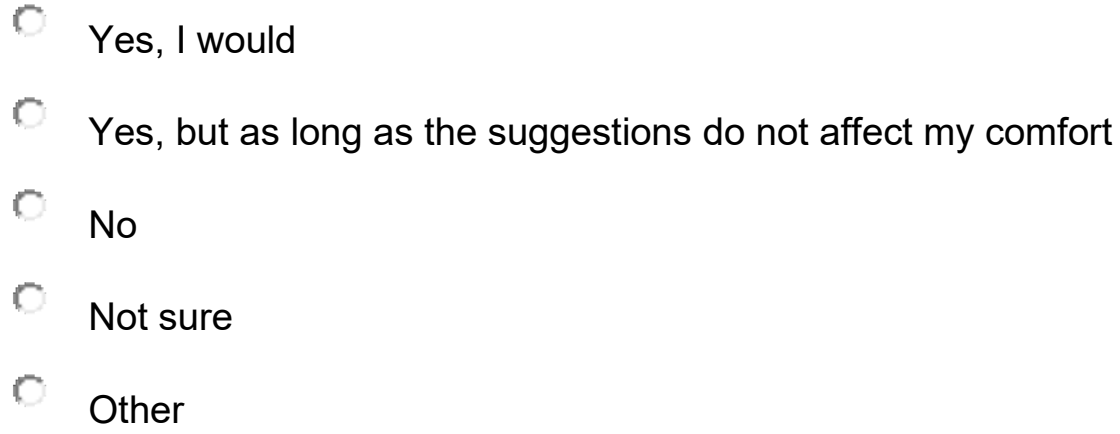

9. Please rank the importance of the below feature from least (1) to most (5) important.

\begin{tabular}{l|l|l|l|l|l|l|} 
& $\mathbf{1}$ & $\mathbf{2}$ & $\mathbf{3}$ & $\mathbf{4}$ & $\mathbf{5}$ \\
\hline $\begin{array}{l}\text { Receiving suggestions to help you save energy from } \\
\text { external sources in forms such as videos and blogs? }\end{array}$ & $\Gamma$ & - & & & & \\
\hline
\end{tabular}

10. What type of fuel would like to receive or share information on? (Check all that apply)

Gas

$\Gamma$ Electricity

Other 
11. What types of information that you are willing to share/know? (Check all that apply)

Cost of your energy usage

Quantity of your energy usage in kWh (meter readings)

$\Gamma \quad$ Information about your heating system (e.g. Type of boiler)

$\Gamma$ Information about your main home appliances (e.g. Fridge and Cooker)

$\Gamma$ Your home energy rating (e.g. A+, C, D, etc...)

$\Gamma$ Actions made to save energy consumption (e.g. changing old light bulbs to LED)

$\Gamma$ Other

12. Do you think ranking households based on their energy consumption (from the lowest to the highest) would help them engage in reducing their home energy consumption?

\footnotetext{
Yes, it definitely would.

No

Yes, but only if there is a reward

No, even if there is a reward

Other
}

\section{Section 3: Personal information}

13. What is your gender?

Male
6 Female 
14. Which of the following categories best describe your age?
Under 21
(C) $21-24$
(C) 25-34
(C) $35-44$
(C) $45-54$
(C) $55-64$
65 Or Older

15. What is your occupation?
Student
Employee
Self-employed
Retired
Other

16. What is your level of education?
Secondary/High School
College
Bachelor
(C) Masters/PhD
Other

17. Please, you can use this comment box for any comments or suggestions you would like to add?

Type your answer here 


\section{Appendix B}

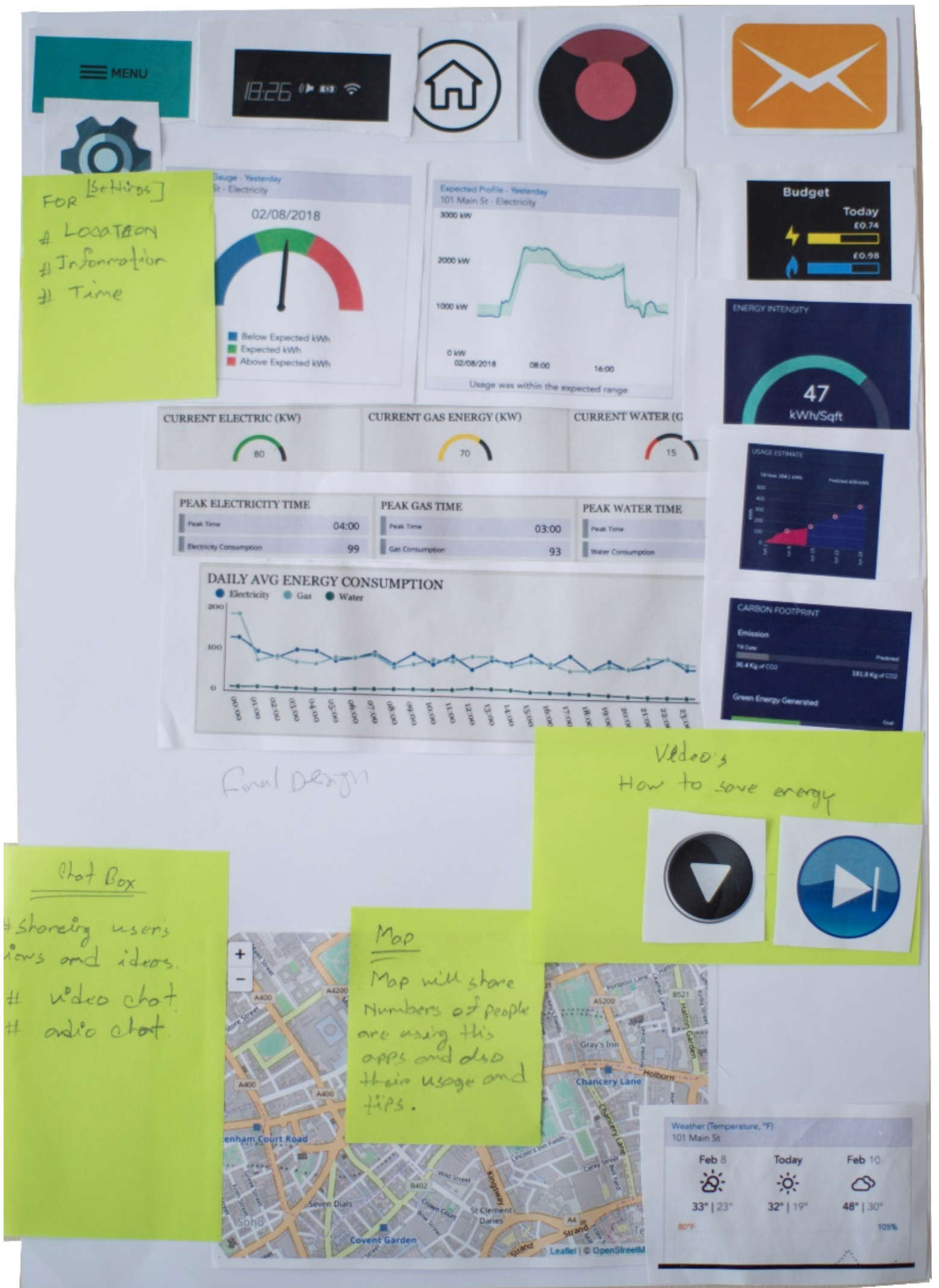

Figure 4.close-up image of interface proposal 1 


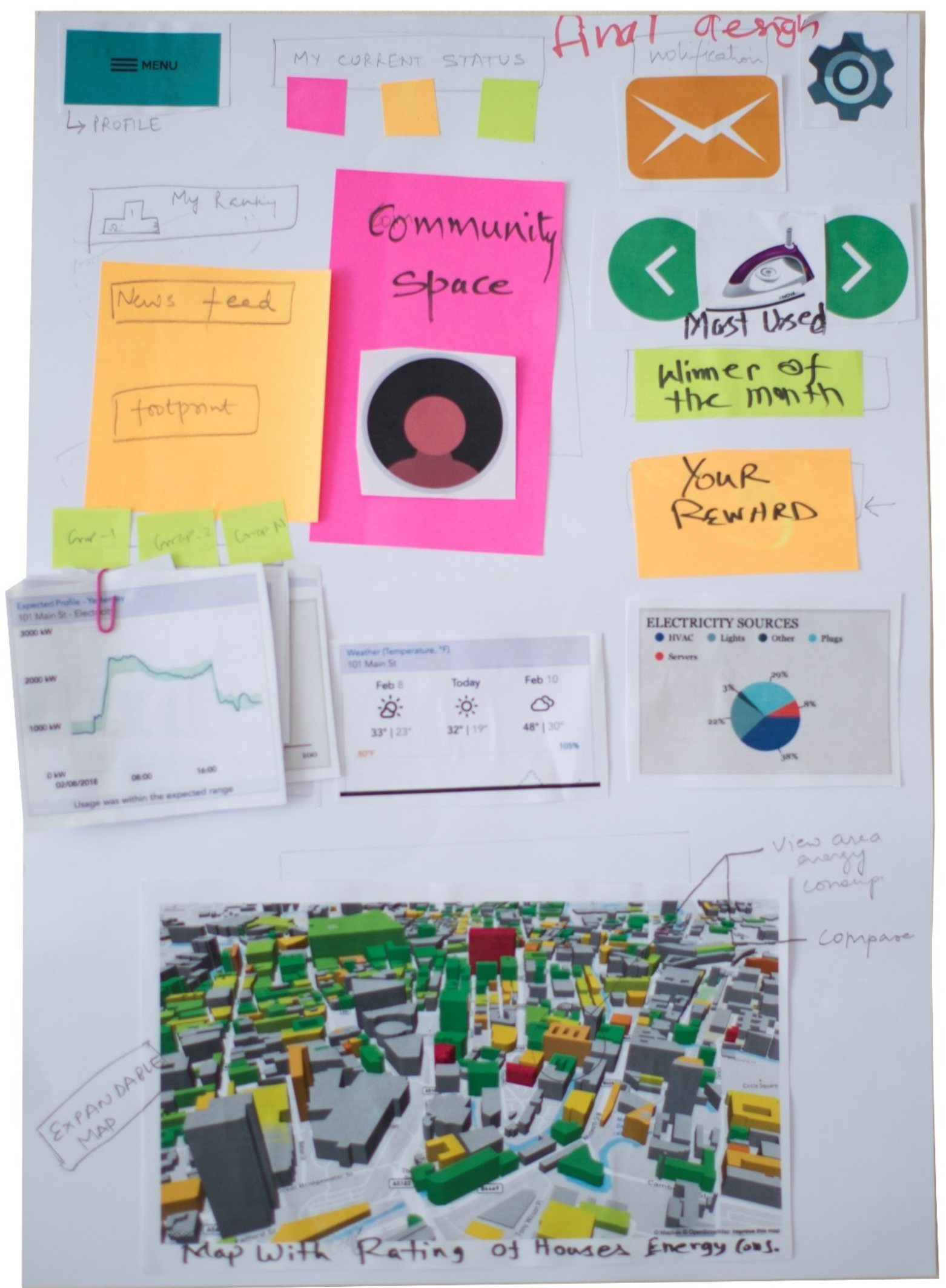

Figure 5. Close-up image of interface proposal 2 


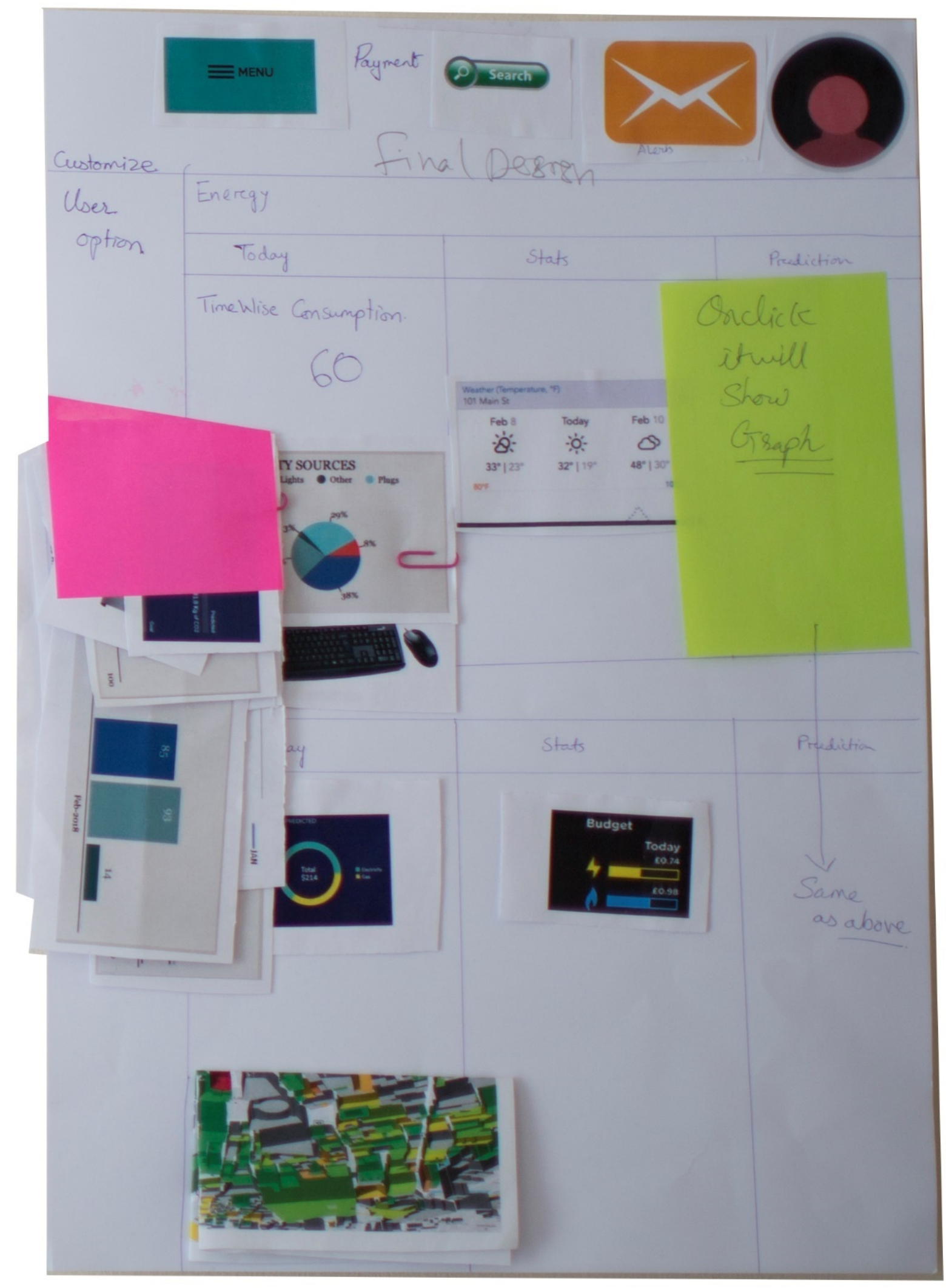

Figure 6.Close-up image of proposal 3 